\title{
A cohort analysis of subjective wellbeing and ageing: heading towards a midlife crisis?
}

Steffen Otterbach Institute for Health Care \& Public Management, University of Hohenheim, Germany steffen.otterbach@uni-hohenheim.de

Alfonso Sousa-Poza Institute for Health Care \& Public Management, University of Hohenheim, Germany Valerie Møller Quality of Life Studies, Institute of Social and Economic Research (ISER), Rhodes University, South Africa

(Received March 2018 Revised July 2018)

http://dx.doi.org/10.14301/llcs.v9i4.509

\begin{abstract}
Using eight waves from the German Panel Analysis of Intimate Relationships and Family Dynamics (pairfam), we analyse how different domains of subjective wellbeing evolve within seven years (2008-2015) in three different cohorts born 10 years apart $(1971 / 73,1981 / 83$, and 1991/93). This study contributes to the ongoing debate about subjective wellbeing following a U-shaped pattern over the life course. In four domains our results show the first half of such a U-shaped pattern: on average, general life satisfaction - as well as satisfaction with leisure time, social contacts and friends, and family - declines substantially between the ages of 15 and 44 , with the most significant decrease taking place at a young age (early 20s). Nevertheless, trajectories among the three cohorts differ markedly, indicating that, ceteris paribus, responses on subjective wellbeing differ greatly between cohorts born just a decade apart. The results further indicate that the two older cohorts assess family life and social contacts more favourably than the youngest cohort.
\end{abstract}

\section{Keywords}

Subjective wellbeing domains; life satisfaction; ageing, longitudinal data, pairfam survey; Germany

\section{Introduction}

Although a large body of psychological literature addresses the midlife crisis (see Brim, 1992; Wethington, 2000), its existence is frequently questioned (e.g. Chiriboga, 1997; McCrae \& Costa, 1990). Nevertheless, much popular discourse acknowledges a period of unhappiness, stress, personality changes and difficulties encountered around the age of 40. Wethington (2000), for example, provides evidence that over a quarter of all Americans report having experienced a crisis at midlife. ${ }^{1}$ Blanchflower and Oswald (2008) also show for a large sample from the UK Labour Force Survey that the incidence of depression and anxiety follows an inverse U-shape and peaks at around the age of
46. Much research in several disciplines on the evolution of subjective wellbeing (SWB) across the lifespan also documents a U-shaped relation between SWB and age, with the minimum generally encountered around middle age (Bauer, Cords, Sellung, \& Sousa-Poza, 2015; Blanchflower \& Oswald 2008; Lang, Llewellyn, Hubbard, Langa, \& Melzer, 2011; López Ulloa, Møller, \& Sousa-Poza, 2013).

Studies on the U-shaped relation between SWB and age tend to use either cross-sectional data or panel data from existing surveys. In their seminal paper, Blanchflower and Oswald (2008) analysed a cross-sectional sample of over 500,000 individuals 
in the United States and Europe. In the United States, depending on the specification, males reach their minimum life satisfaction at between 36 and 53 years of age, whereas women reached a minimum at 39. In Europe, wellbeing reached a minimum at around 45. Much of the related literature relied on data from long-running panels, such as the British Household Panel (Cheng, Powdthavee, \& Oswald, 2017; Clark, 2007; Clark \& Oswald, 1994; McAdams, Lucas, \& Donnellan, 2012), the German Socio-Economic Panel (Cheng et al., 2017; Frijters \& Beatton, 2012; Gwozdz \& SousaPoza, 2010; Kassenboehmer \& Haisken-DeNew, 2012; Van Landeghem, 2008, 2012), the U.S. General Social Survey (Easterlin, 2006; Easterlin \& Sawangfa, 2007) or the Panel Survey of Household Income Labour Dynamics in Australia (Cheng et al., 2017; Frijters \& Beatton, 2012). Although much of the evidence points to a U-shape, conflicting evidence exists. Depending on the data used, the definition of wellbeing, estimation technique, and choice of covariates, several different forms can be observed. As pointed out by López Ulloa et al. (2013, p. 240), "it is difficult to say with certainty whether the relationship between age and wellbeing across the lifespan is linear or convex".

Much of this controversy can be attributed to the fact that, ideally, the analysis of SWB across the lifespan should be conducted using long-running panels that follow representative individuals over the entire lifetime (Frijters \& Beatton, 2012). The main advantage of such data is the ability to directly control for 'cohort effects,' the potential differences between the SWB of individuals born at a certain point in time under particular circumstances and those born at different times (Schilling, 2005). Unfortunately, such data are rarely available, but some data sets do exist (such as the British National Child Development Study and the British Cohort Study). To our knowledge, Galambos, Fang, Krahn, Johnson, and Lachmann (2015) take the longest perspective into account and use happiness data from the Edmonton Transitions Study, which followed over a 25-year period a group of individuals from working- and middle-class neighbourhoods in a large western city in Canada.

The aim of this paper is to analyse ageing and subjective wellbeing using cohort data that encompass all ages between 15 and 43. Specifically, we analyse how different SWB domains evolve within seven years in three different cohorts born
10 years apart (1991-1993, 1981-1983 and 19711973). Although our three cohorts do not follow individuals throughout their entire life, following them over seven years has the distinct advantage over existing studies that we can analyse large samples of a single cohort over a relatively long timespan.

Our contribution is thus twofold: first, by analysing specific cohorts, we are able not only to take cohort effects directly into account but also to assess how strong such cohort effects may be. Although past research has documented the existence of cohort effects (e.g. Blanchflower \& Oswald, 2008; Clark, 2007; Gwozdz \& Sousa-Poza, 2010), by actually following different cohorts across time we are able to get a much clearer picture of these cohort effects. Second, by focusing on several life satisfaction domains, we are able to shed light on the trajectories of global life satisfaction across the lifespan. Thus, an analysis on global life satisfaction masks developments in specific domains that could provide an answer to the origins of changes in global life satisfaction. The influence of different domains will most probably not only change across the lifespan, but may also compensate each other (Theuns, Baran, van Vaerenbergh, Hellenbosch, \& Tilinouine, 2012; Theuns, Hofmans, \& Verresen, 2007). Yet, with a few notable exceptions (Easterlin, 2006; Easterlin \& Sawangfa, 2007; McAdams et al., 2012), little research takes a disaggregated approach, i.e. analyse the development of specific domains across time. None to our knowledge analyse domains with longitudinal data and, in particular, with a cohort approach taken in this study.

\section{Conceptual framework}

Several theories have been put forward in order to explain how wellbeing progresses through the lifecycle, and also why a midlife crisis may occur (see the literature review in López Ulloa et al., 2013). According to one socioeconomic theory, younger individuals may have higher expectations than their elders, which may not be met, leading to a drop in wellbeing in younger years. This decline continues as long as aspirations are not being met. In a related train of thought, problems can occur at the midlife transition around age 40 when an individual perceives personal growth as stymied or thwarted (Levinson \& Levinson, 1996). The gerontology literature has also highlighted this process whereby older individuals learn to adapt to 
their strengths and weaknesses and thus have more realistic aspirations, which can raise wellbeing as they age. According to Argyle (2001) happiness increases slightly with age, mainly due to a declining goal-achievement gap. This thus offers an explanation as to why wellbeing rises after middle age. Similarly, Charles and Carstensen's (2009) socio-emotional selectivity theory emphasises that, with passing time and shrinking time horizons, individuals experience more life satisfaction as age increases because they spend more time in activities that contribute more directly to their wellbeing.

There is also some evidence that happy people live longer, which could also increase wellbeing in older age. In their meta-analysis, Howell, Kern, and Lyubomirsky (2007) show that probability of living longer increases by $14 \%$ for individuals with high wellbeing compared to those with low wellbeing. In a survey of people living in industrial countries, happier people enjoy an increased longevity of between 7.5 and 10 years, a strong effect comparable to smoking or not (Veenhoven, 2008).

An alternative suggestion is that the midlife crisis is a response to the realisation of approaching death (Jaques, 1965), although the increase in life expectancy well beyond what is considered middle age has rendered this explanation somewhat obsolete (Wethington, 2000). However, evolution may also play a role. In their study that analyses the wellbeing of 508 great apes, Weiss, King, InoueMurayama, Matsuzawa, and Oswald (2012) show that a midlife crisis also appears to exist among these species. One possible explanation is that evolutionary selection of individuals that have a higher wellbeing at young and old ages may take place, as "these individuals, being satisfied at stages of their life where they have fewer resources to improve their lot, would be less likely to encounter situations that could be harmful to them or their kin." (Weiss et al., 2012, p. 19950).

Media coverage of the midlife crisis may also accentuate this 'crisis', i.e. personal experiences around middle age may be influenced by "social commentators and media pundits, in search of opportunities to market information as products, arouse 'moral insecurities' that evoke a culture of fear. These fears create panic over aging, even when life is going well" (Wethington, 2000, p. 88).

It must also be stressed that some theories from different disciplines do not posit a midlife crisis. The most prominent economic theory is the "life cycle hypothesis" (Modigliani \& Brumberg, 1954) which, simply stated, assumes that individuals try to smooth consumption across the lifecycle and in doing so try to maintain a constant utility (i.e. wellbeing) level. Taken at face value, one would thus not expect changes in wellbeing across the lifecycle. The assumptions underlying this theory are, however, quite stringent and loosening them gives rise to more differentiated results. However, as pointed out by Blanchflower and Oswald (2008), "textbook economic analysis is not capable [...] of producing unambiguous predictions about the pattern of well-being through life" (Blanchflower \& Oswald, 2008, p. 1735). There are also psychological theories that primarily stress the stability of wellbeing across time. A prominent theory is the set point theory, which argues that individuals are born with a predisposition to a certain level of happiness, based on genetics and personality (e.g. Brickman, Coates, \& Janoff-Bulman, 1978; Clark \& Georgellis, 2012). Changes in wellbeing should thereby only be temporary, and always revert back to a baseline level that is determined biologically. Also known as "hedonic adaptation", this is a process whereby "individuals return to baseline levels of happiness following a change in life circumstances" (Lucas, 2007 , p. 75). Even as early as 1999, Diener and Lucas (1999, p. 227) argued that "the influence of genetics and personality suggests a limit on the degree to which policy can increase subjective wellbeing [...] Changes in the environment, although important for short-term well-being, lose salience over time through processes of adaptation, and have small effects on long-term subjective wellbeing".

In conclusion, one can state that there are numerous, yet often contradictory, theories from several disciplines that explain the passage of wellbeing across the lifecycle. As pointed out by Weiss et al. (2012), there is still little convergence of explanations about the origins of the midlife crisis.

\section{Methods and data}

The strand of literature on the relation between happiness and age - also referred to as the mysterious U-shaped relation (Frijters \& Beatton, 2012) or the age-happiness puzzle (Li, 2016) - is characterised by a broad discussion on appropriate methodology. In general, this discussion reflects the different views on whether the focus of analytical interest should be happiness over the life course 
per se (Baetschmann, 2014; Easterlin, 2006; Glenn, 2009) or an isolated pure age effect net of all other influences and life-course events (Blanchflower \& Oswald, 2008). Adherents of the Easterlin tradition point out that such events as leaving school, securing a first job and subsequent job promotions, getting married, having children, getting divorced, being widowed, experiencing a health decrease and even becoming frail at a particular life stage are natural features of the life course. They therefore argue that these immanent life course events should not be controlled away (Hellevik, 2017). Glenn (2009), for example, in his response to Blanchflower and Oswald (2008), argues that the Ushape is merely the result of using inappropriate control variables. Likewise, Kassenboehmer and Haisken-DeNew (2012) emphasise the importance of controlling for unobserved heterogeneity and taking into account time-invariant individual fixedeffects. Using data from the German SocioEconomic Panel (SOEP) Study, these authors conclude that the U-shape becomes flat once fixedeffects are controlled for. Conversely, Frijters and Beatton (2012), in an analysis of three well-known panel data sets (the SOEP, the Household, Income and Labour Dynamics in Australia (HILDA) Survey, and the British Household Panel Survey (BHPS)), show that the U-shape is deepened by the addition of control variables commonly used in life satisfaction analyses.

In the discussion of appropriate control variables, it is generally agreed that controlling for cohort effects is central (Baetschmann, 2014; Blanchflower \& Oswald, 2008; Glenn, 2009), reflecting the fact that individuals born at a certain point in time and under particular circumstances may differ in subjective wellbeing from those born at different times. However, the linear dependency of age, cohort and time creates a problem of multidimensionality. That is, whereas in a cross-sectional setting, age perfectly corresponds to birth year, in a longitudinal setting, it is a linear combination of cohort and time. As a result, any attempt to construct broader categories of age and cohort to allow for some variation (e.g. Oswald, 2008) creates more or less serious problems of multi-collinearity (Glenn, 2009). Hence, in the age-period-cohort conundrum, simultaneous identification of these three effects is impossible. In fact, Baetschmann (2014) even argues that this isolated pure and under-identified age effect is uninteresting and its interpretation unmeaningful simply because 'it is not possible to become older without proceeding in time' (p. 397).

\section{Methods}

In line with this literature, we use three different but related methods applied to each cohort separately. First, we specify a simple Ordinary Least Squares (OLS) model using the age groups as categorical dummy variables with no additional control variables. The predictions from such a model are equal to the unconditional means of SWB over the age groups. As no control variables are included (i.e. the natural features of the life course are not controlled away), the argument that the observed trends in subjective wellbeing are a mere result of (inappropriate) control variables does not hold for this approach. Second, following the strand of literature arguing that consideration of control variables is essential, we next examine whether the observed trends in SWB are confounded by the inclusion of other influences on SWB. Thus, we estimate OLS regressions using commonly accepted control variables, as well as a health measure (see Frijters \& Beatton, 2012). We also include Gross Domestic Product (GDP) per capita and unemployment rates as macro-economic control variables on the federal state level. Here, standard errors are adjusted for within-person clustering of observations. Lastly, we estimate fixed-effects regressions, which enable us to hold unobserved heterogeneity constant, again including the same set of time-variant socio-economic control variables and federal-level macro controls. We thus limit our OLS analyses to time-variant control variables in order to focus on how model predictions change conditional on fixed effects when all else is equal. Thereby we acknowledge that controlling for unobserved heterogeneity might be particularly important. Our models can be expressed as follows:

$$
S W B_{i t}=\beta X_{i t}+\gamma Z_{k t}+\phi_{t}+\alpha_{i}+\varepsilon_{i t}
$$

where $S W B_{i t}$ is a measure of subjective wellbeing (overall life satisfaction or domain satisfaction), $X_{i t}$ is a vector of the time-variant control variables, and $Z_{\mathrm{kt}}$ is a vector of the time-variant macroeconomic control variables (GDP per capita and unemployment rates) on the federal state level. Once we control for these latter, $\phi_{t}$ corresponds to the age groups of the respective cohorts and captures any remaining time-specific (survey wave) effects, thus identifying any potential non-linear age effects. While other studies used second or higher 
degree polynomials (e.g. Li, 2016; Wooden \& Li, 2014; Frijters \& Beatton, 2012) to approximate and thereby smoothly interpolate the relationship between age and subjective wellbeing, we model age in a non-parametric way. Thus, we do not make any assumption about the functional form of the underlying relationship and allow the effect of age on SWB to vary in the most flexible way. Random errors are denoted by $\varepsilon_{i t}$, and individual fixed effects by $\alpha_{i}$, which in the pooled OLS estimation, is restricted to zero (i.e., excluded from the model). The $X_{i t}$, and $Z_{k t}$ vectors are also restricted to zero in estimations of the mean.

In principle, the ordinal feature of our dependent SWB variables would require a nonlinear estimation method such as ordinal logit. However, as in many other studies (e.g. Wooden \& Li (2014) or Kassenboehmer \& Haisken-DeNew (2012)) we treat our dependent variables as cardinal (i.e. as a discrete ratio scale). For the ease of interpretation and comparability to other studies we follow Ferrer-i-Carbonell and Frijters (2004) who show that it makes only minor differences regarding the results whether ordinality or cardinality are assumed. All estimations are carried out for both men and women, as well as for the three cohorts separately. The results are presented graphically as the unconditional mean and the model predictions over the age groups, respectively. Because individuals grow older as time proceeds, in this specific setting, age and time are non-separable dimensions.

\section{Sample}

The analyses are based on release 8.0 data (Brüderl et al., 2017) from the first eight waves of the German Panel Analysis of Intimate Relationships and Family Dynamics (pairfam) ${ }^{2}$, a longitudinal nation-wide survey aimed at providing an empirical data base for the study of partnership and family dynamics. Begun in 2008 and collected annually ever since, at baseline, pairfam surveyed about 12,000 randomly selected respondents (anchor persons) among three cohorts born 1971-73 (4,054 individuals), 1981-83 (4,010 individuals) and 199193 (4,338 individuals). Although corrected panel attrition rates stabilised around $10 \%$ after wave 3 , by wave 6 more than half of the original pairfam sample had been lost (Brüderl et al., 2017). From wave two on pairfam is complemented by the Demographic Differences in Life Course Dynamics in Eastern and Western Germany (DemoDiff) panel study, which follows closely the design of pairfam but only samples the cohorts 1971-1973 and 19811983. Initiated and funded by the Max Planck institute for Demographic Research, DemoDiff has been fully integrated in pairfam and from wave 5 onwards its respondents are regarded as regular pairfam respondents (Brüderl et al., 2017). The cohort-sequential design of the study with its adjacent segments regarding the three age groups is illustrated in figure A.1. Data were collected by mode of computer-assisted personal interviewing (CAPI) among respondents living in private households in Germany with sufficient language skills to follow the German-speaking interview. As can be seen in graph A.1 in the appendix, the cohorts do not (yet) overlap. However, the cohorts "touch each other", which allows us to assess with reasonable confidence whether or not trajectories for the different cohorts differ.

\section{Measurement of subjective wellbeing}

In addition to a wealth of variables describing family and partnership dynamics, pairfam offers rich information on several domains of wellbeing and satisfaction. In particular, at the beginning of the interview, respondents are asked, 'How satisfied are you with the following domains of your life?': (i) school, education, career; (ii) leisure activities, hobbies, interests; (iii) friends, social contacts; and (iv) family. The interview concludes with the question, 'All in all, how satisfied are you with your life at the moment?' All these satisfaction domains are surveyed on an 11-point scale ranging from 0 (very dissatisfied) to 10 (very satisfied). Our choice of domains is thus primarily data driven, and we acknowledge that several important domains (e.g. satisfaction with income or health) are not covered by our analysis.

We use single-item measures for subjective wellbeing. It could be argued that multi-item measures such as the satisfaction with life scale (Diener, Emmons, Larsen, \& Griffin, 1985) consisting of multiple questions provide advantageous psychometric properties to cover the multidimensional aspects of subjective wellbeing compared to single-item scales (Jovanovic 2016). However, it has been shown that single item measures for life satisfaction and subjective wellbeing have strong correlations with and good reliability compared to multi-item measures of life satisfaction (Robustellie \& Whisman, 2016). 


\section{Covariates}

The analysis does, however, include a parsimonious set of socio-economic covariates that are widely used as standard control variables, as well as a measure of health (Frijters \& Beatton, 2012). The explanatory variables are marital status ('married' or 'not married'), number of children, and self-rated health status within the last four weeks. This latter is measured on a five-point scale ('poor', 'suboptimal', 'satisfactory', 'good', 'excellent') that is then recoded into a binary good/poor health dummy based on the first and last two categories, respectively, with satisfactory health as the reference category. Further control variables include being unemployed ('yes' or 'no'), not being in the labour force ('yes' or 'no'), and the natural logarithm of equivalised net household income, which is adjusted to household structure according to the modified Organization of Economic Co-operation and Development (OECD) scale. We also control for whether another person was present during the interview. Finally, to capture wealth and period effects related to the business cycle, we also include GDP per capita and unemployment rates on the federal state level. As Baetschmann (2014) points out, capturing these effects is particularly important when the observation period is short but encompasses the European economic crises. Summary statistics describing the SWB domains and all covariates are given in table 1.

\section{Results}

Figure 1 depicts the results for life satisfaction (with corresponding tables for all figures provided in the appendix and regression results for the full samples provided in a supplementary appendix). Although a cursory glance at the first wave results for each cohort suggests a downward movement in life satisfaction (fixed-effects predictions of 7.78, 7.47 and 7.48 for the 1991/93, 1981/83 and $1971 / 73$ cohorts, respectively), the changes within a cohort suggest that a strong decline in life satisfaction takes place only in the youngest cohort. In the other two cohorts, the relation remains quite flat. This drop in the youngest cohort is quite large, about $0.37,0.32$, and 0.14 points within seven years for the unconditional and conditional values, respectively. For the middle cohort, life satisfaction remains quite flat, and the oldest cohort experiences a slight decrease. Life satisfaction thus declines substantially between the ages of 15 and
24 (covered by the young cohort) and then remains relatively flat until the age of 44 (covered by the middle and old cohorts). This is in accordance with the left-hand side of the U-shaped relation between age and life satisfaction. As can be seen by the confidence intervals, most changes in these two older cohorts are not significant. This pattern is similar for men and women but more pronounced for males. When comparing life satisfaction (OLS and fixed-effects results) in the eighth wave of the first cohort with the first wave of the second cohort, we do not observe a major 'jump' in life satisfaction, implying that cohort effects are most probably quite negligible between these two cohorts. This being the case, it appears that the strong decline in life satisfaction in young years levels out at about the age of 24 or 25 .

A different pattern emerges, however, for satisfaction with school, education and career (see figure 2), which increases in younger years by about 0.24 and 0.14 points for the fixed-effects predictions and unconditional mean, respectively, but changes less sharply in the two older cohorts (differences insignificant). Nevertheless, we observe a marked cohort effect between the young and middle cohorts, with a large and significant drop in the fixed-effects predictions and unconditional means by 0.41 and 0.36 points, respectively. This pattern is more or less equal for both genders.

Figure 3 shows the results for satisfaction with leisure activities, hobbies and interests, the first of which shows a steep decline in the early years that tends to level off around the late 20s. Although this finding holds true for both men and women, no strong cohort effects are observable in this domain. This pattern is similar to the analysis of both amount and use of leisure time by McAdams et al. (2012) using BHPS data.

A strong downward trend is also apparent in all cohorts and for both men and women with respect to satisfaction with social contacts and friends (see figure 4). Within all cohorts, this domain drops significantly by between 1.07 (unconditional mean of the young cohort) and 0.45 points (fixed-effects predictions of the oldest cohort) in a pre-midlife decline that is also reported by McAdams et al. (2012) in their analysis of the domain social life. In this domain, assessments are more favourable among the two older cohorts, signalling a slight cohort effect between the middle and old cohort, especially in the female sample. 
Table 1. Descriptive statistics: number of observations, means, standard deviations

\begin{tabular}{|c|c|c|c|c|c|c|c|c|c|c|c|c|}
\hline \multirow[b]{2}{*}{ Variable } & \multicolumn{3}{|c|}{ Cohorts pooled } & \multicolumn{3}{|c|}{ Cohort 1991-93 } & \multicolumn{3}{|c|}{ Cohort 1981-83 } & \multicolumn{3}{|c|}{ Cohort 1971-73 } \\
\hline & Obs & Mean & SD & Obs & Mean & SD & Obs & Mean & SD & Obs & Mean & SD \\
\hline Life satisfaction & 65,236 & 7.57 & 1.69 & 21,842 & 7.82 & 1.53 & 20,812 & 7.46 & 1.74 & 22,582 & 7.42 & 1.78 \\
\hline Job satisfaction & 64,952 & 7.23 & 2.16 & 21,817 & 7.43 & 2.02 & 20,709 & 7.12 & 2.25 & 22,426 & 7.15 & 2.20 \\
\hline Satisfaction with leisure & 65,264 & 7.04 & 2.15 & 21,857 & 7.64 & 1.94 & 20,826 & 6.83 & 2.15 & 22,581 & 6.66 & 2.23 \\
\hline Satisfaction with social contacts & 65,278 & 7.74 & 1.96 & 21,862 & 8.33 & 1.67 & 20,831 & 7.56 & 1.99 & 22,585 & 7.34 & 2.07 \\
\hline Satisfaction with family & 65,254 & 8.38 & 1.81 & 21,860 & 8.49 & 1.67 & 20,824 & 8.34 & 1.86 & 22,570 & 8.31 & 1.88 \\
\hline Unemployed & 65,309 & 0.05 & 0.22 & 21,867 & 0.03 & 0.16 & 20,843 & 0.08 & 0.27 & 22,599 & 0.05 & 0.22 \\
\hline Not in labour force & 65,309 & 0.30 & 0.46 & 21,867 & 0.59 & 0.49 & 20,843 & 0.19 & 0.40 & 22,599 & 0.11 & 0.31 \\
\hline Married & 65,309 & 0.33 & 0.47 & 21,867 & 0.01 & 0.08 & 20,843 & 0.32 & 0.47 & 22,599 & 0.63 & 0.48 \\
\hline Number of chidlren & 65,299 & 0.79 & 1.11 & 21,865 & 0.02 & 0.17 & 20,841 & 0.68 & 0.97 & 22,593 & 1.62 & 1.19 \\
\hline Self-rated health & 65,240 & 3.74 & 0.98 & 21,845 & 3.87 & 0.98 & 20,813 & 3.74 & 0.98 & 22,582 & 3.62 & 0.97 \\
\hline Good health & 65,240 & 0.66 & 0.47 & 21,845 & 0.70 & 0.46 & 20,813 & 0.66 & 0.47 & 22,582 & 0.62 & 0.49 \\
\hline Satisfactory health & 65,240 & 0.22 & 0.41 & 21,845 & 0.19 & 0.39 & 20,813 & 0.21 & 0.41 & 22,582 & 0.24 & 0.43 \\
\hline Bad health & 65,240 & 0.12 & 0.33 & 21,845 & 0.11 & 0.31 & 20,813 & 0.12 & 0.33 & 22,582 & 0.14 & 0.34 \\
\hline Net equivalised h'hold income & 52,478 & 1542.38 & 1080.19 & 14,683 & 1320.73 & 980.75 & 17,891 & 1556.56 & 1003.36 & 19,904 & 1693.14 & 1184.41 \\
\hline Ln net equivalised $\mathrm{h}$ 'hold income & 52,478 & 7.19 & 0.58 & 14,683 & 7.01 & 0.64 & 17,891 & 7.21 & 0.56 & 19,904 & 7.30 & 0.53 \\
\hline Unemployment rate & 65,300 & 6.73 & 2.84 & 21,867 & 6.35 & 2.68 & 20,838 & 7.01 & 2.94 & 22,595 & 6.83 & 2.85 \\
\hline BIP per capita & 65,300 & 32082.08 & 7042.32 & 21,867 & 33107.71 & 6829.36 & 20,838 & 31564.44 & 7254.06 & 22,595 & 31566.90 & 6937.96 \\
\hline Year 2008 & 65,309 & 0.19 & 0.39 & 21,867 & 0.20 & 0.40 & 20,843 & 0.19 & 0.39 & 22,599 & 0.18 & 0.38 \\
\hline Year 2009 & 65,309 & 0.16 & 0.37 & 21,867 & 0.16 & 0.37 & 20,843 & 0.16 & 0.37 & 22,599 & 0.16 & 0.37 \\
\hline Year 2010 & 65,309 & 0.14 & 0.35 & 21,867 & 0.14 & 0.35 & 20,843 & 0.14 & 0.34 & 22,599 & 0.14 & 0.34 \\
\hline Year 2011 & 65,309 & 0.12 & 0.33 & 21,867 & 0.12 & 0.33 & 20,843 & 0.12 & 0.33 & 22,599 & 0.12 & 0.33 \\
\hline Year 2012 & 65,309 & 0.11 & 0.31 & 21,867 & 0.11 & 0.31 & 20,843 & 0.11 & 0.31 & 22,599 & 0.11 & 0.32 \\
\hline Year 2013 & 65,309 & 0.10 & 0.30 & 21,867 & 0.10 & 0.30 & 20,843 & 0.10 & 0.30 & 22,599 & 0.10 & 0.30 \\
\hline Year 2014 & 65,309 & 0.09 & 0.29 & 21,867 & 0.09 & 0.28 & 20,843 & 0.09 & 0.29 & 22,599 & 0.09 & 0.29 \\
\hline Year 2015 & 65,309 & 0.08 & 0.28 & 21,867 & 0.08 & 0.27 & 20,843 & 0.08 & 0.28 & 22,599 & 0.09 & 0.28 \\
\hline
\end{tabular}

Data: German Panel Analysis of Intimate Relationships and Family Dynamics (pairfam), 2008-2015. 
Figure 1. Overall life satisfaction, unconditional mean and model predictions from OLS and FE estimations including 95\% Cls

1991-93

1981-83

1971-73

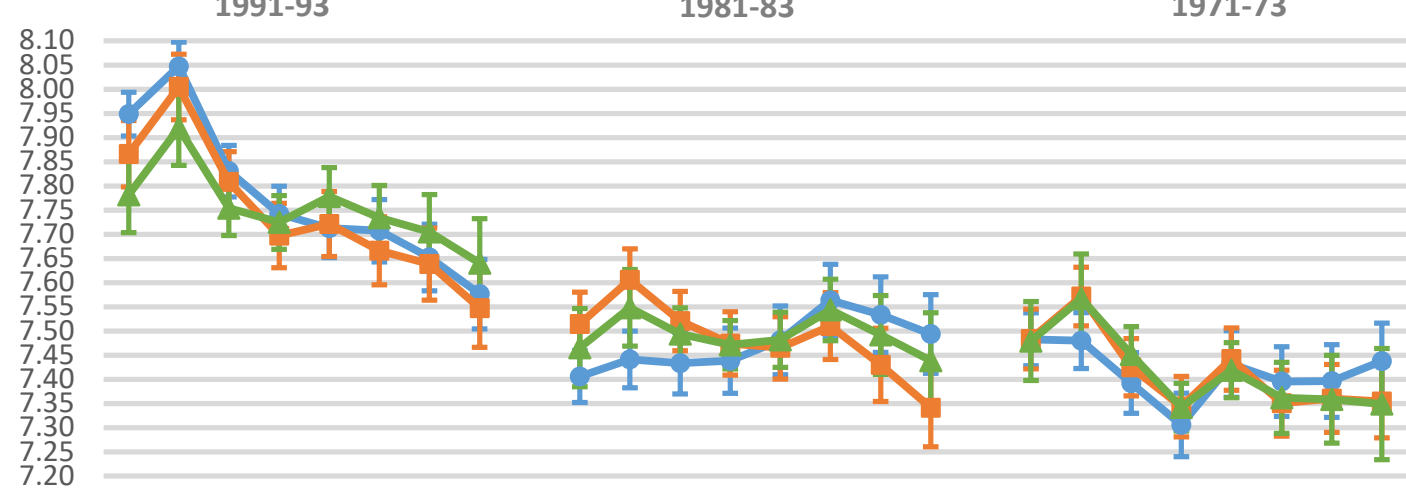

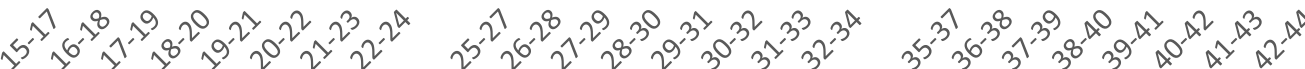

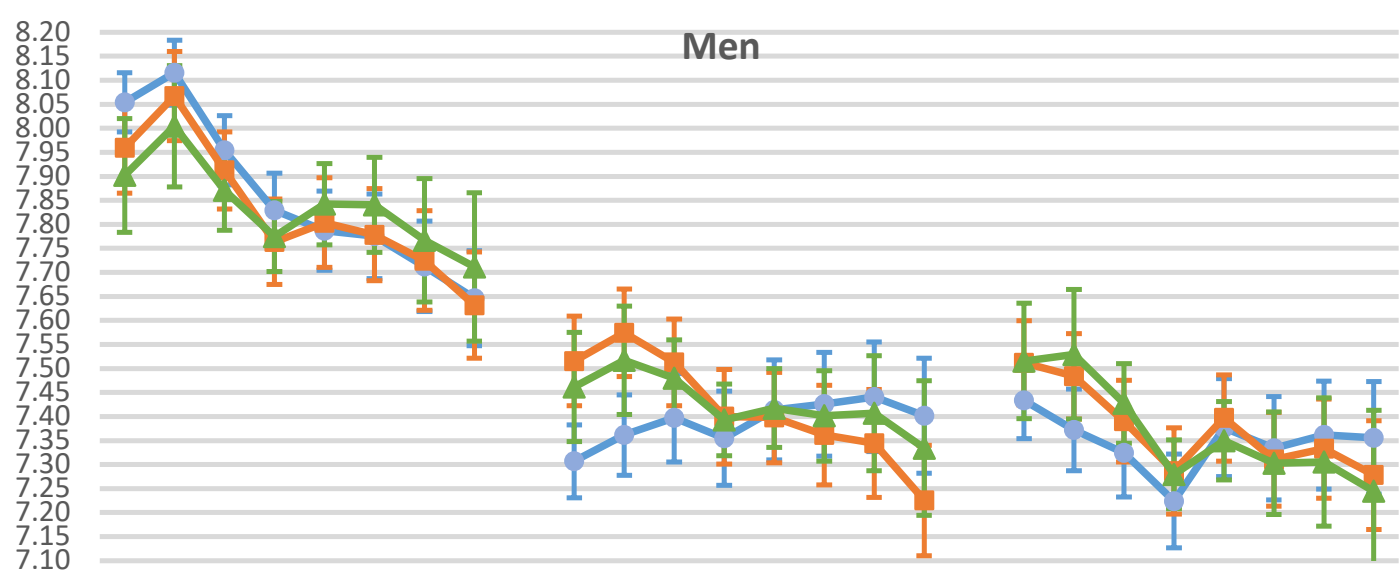

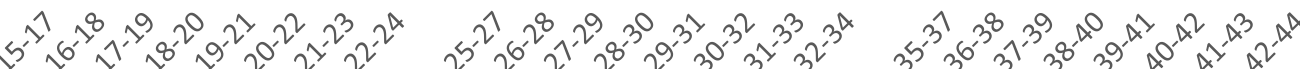

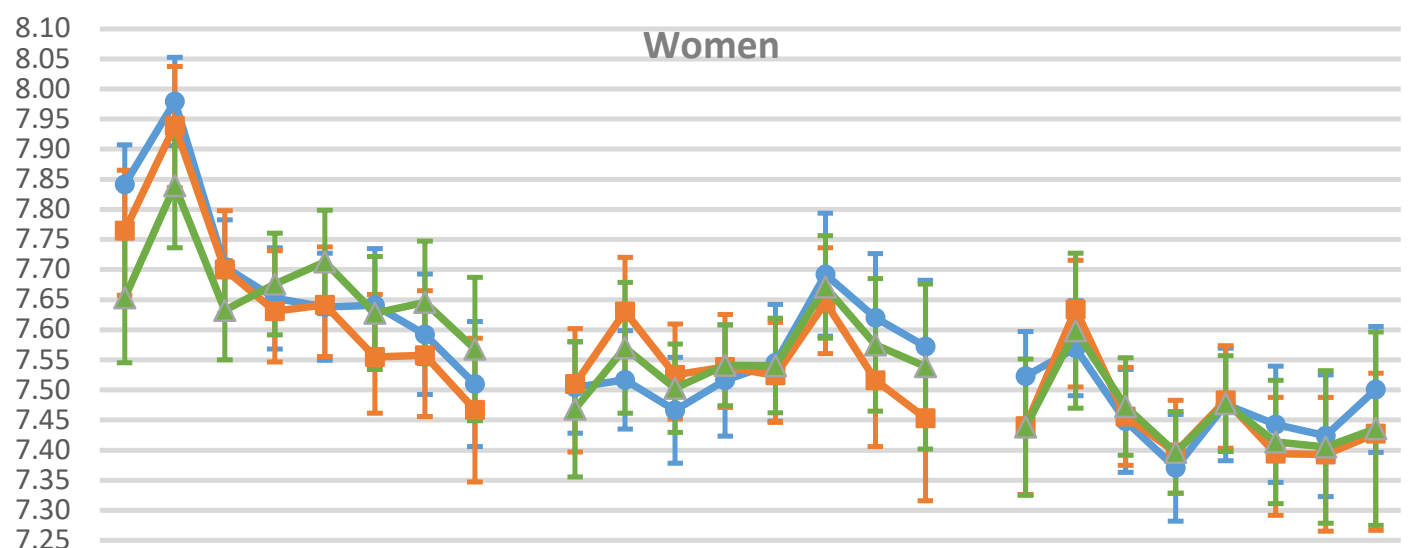

7.25

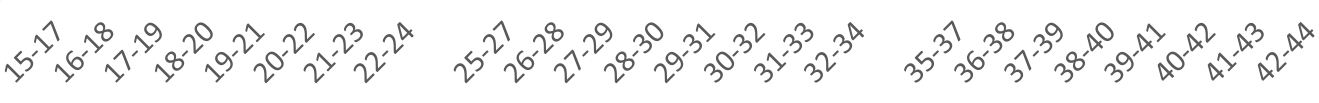$$
\longrightarrow \text { Mean }- \text { OLS } \rightarrow F E
$$

Note: Model predictions include marital status, number of children, self-rated health, employment status (being unemployed, not in the labour force), the natural logarithm of equivalised net household income, whether another person was present during interview, GDP per capita, and unemployment rate as control variables. Full sample (men and women) consists of $21,842,20,812,22,582$ (unconditional mean) and 14,670,17,869, 19,888 (OLS and FE predictions) observations for the three birth cohorts, respectively. 
Figure 2. Satisfaction with job, education, career, unconditional mean and model predictions from OLS and FE estimations including 95\% Cls

1991-93

1981-83

1971-73

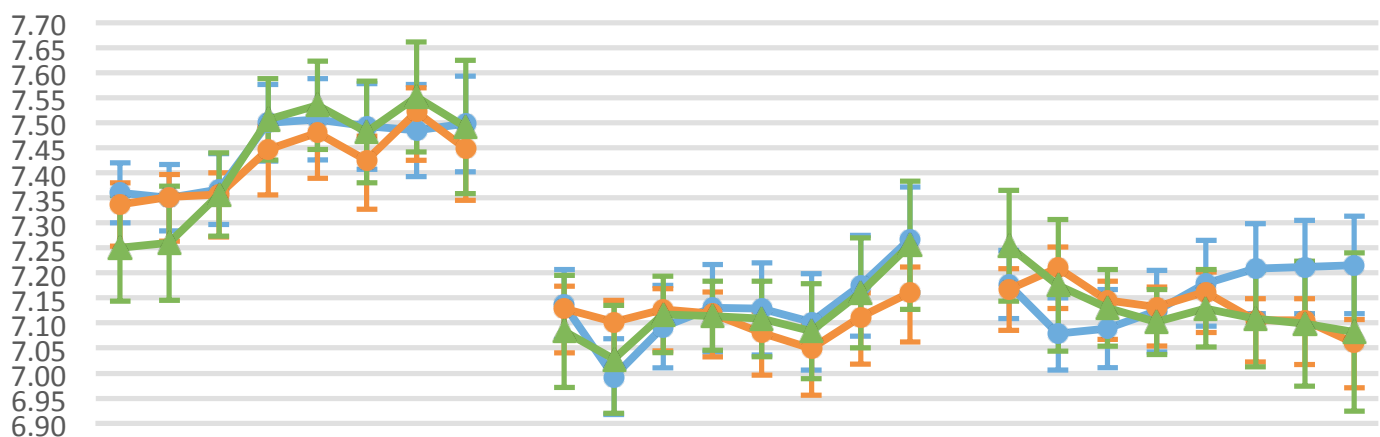

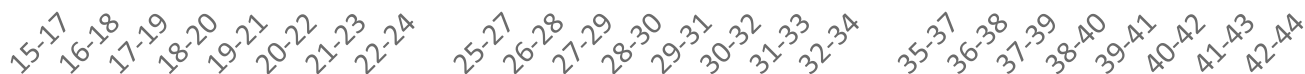

7.80
7.75

7.75
7.70
7.65

7.65

7.60

7.50

7.45

7.40

7.35

7.30

7.25

7.20

7.15

7.10

7.05

7.00

6.95

6.90

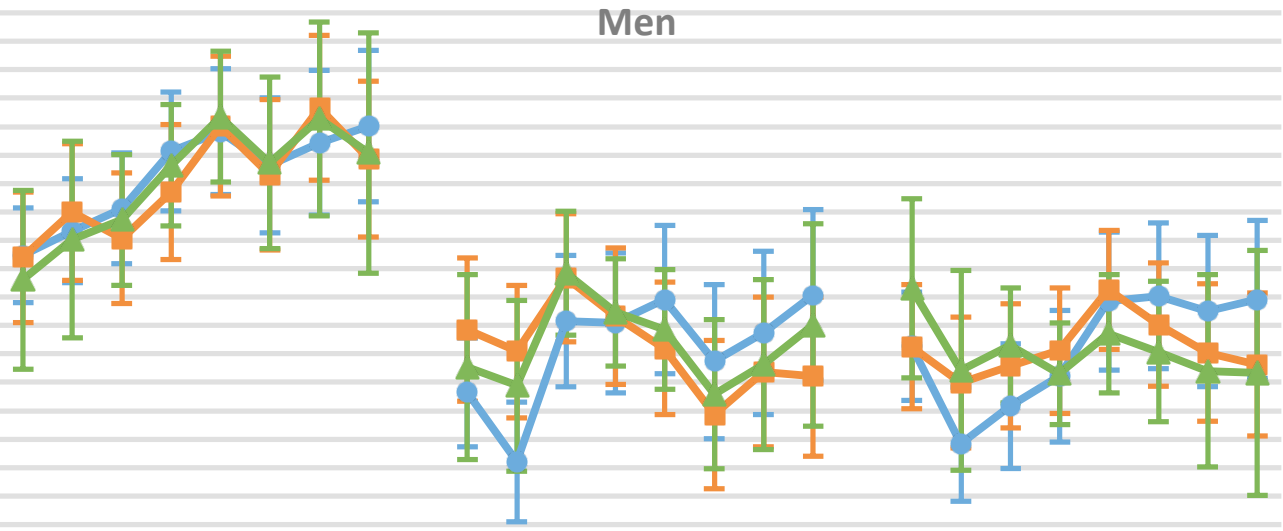

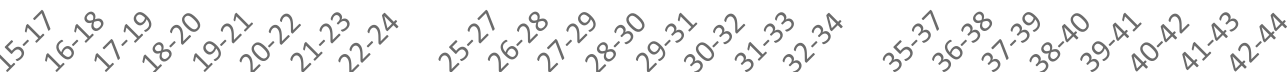

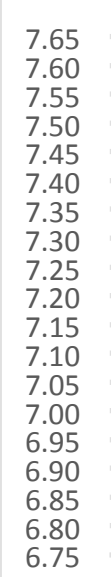

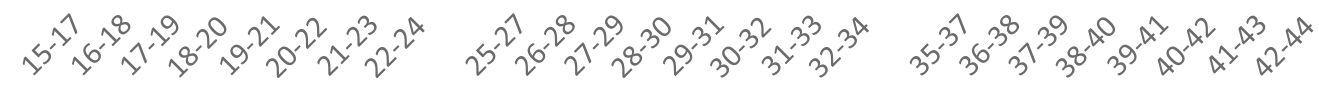

$$
\begin{aligned}
& \longrightarrow \text { Mean }- \text { OLS } \longrightarrow \mathrm{FE}
\end{aligned}
$$

Note: Model predictions include marital status, number of children, self-rated health, employment status (being unemployed, not in the labour force), the natural logarithm of equivalised net household income, whether another person was present during interview, GDP per capita, and unemployment rate as control variables. Full sample (men and women) consists of $21,817,20,709,22,426$ (unconditional mean) and 14,640, 17,763, 19,758 (OLS and FE predictions) observations for the three birth cohorts, respectively. 
Figure 3. Satisfaction with leisure activities, hobbies, interests, unconditional mean and model predictions from OLS and FE estimations including $95 \% \mathrm{Cls}$

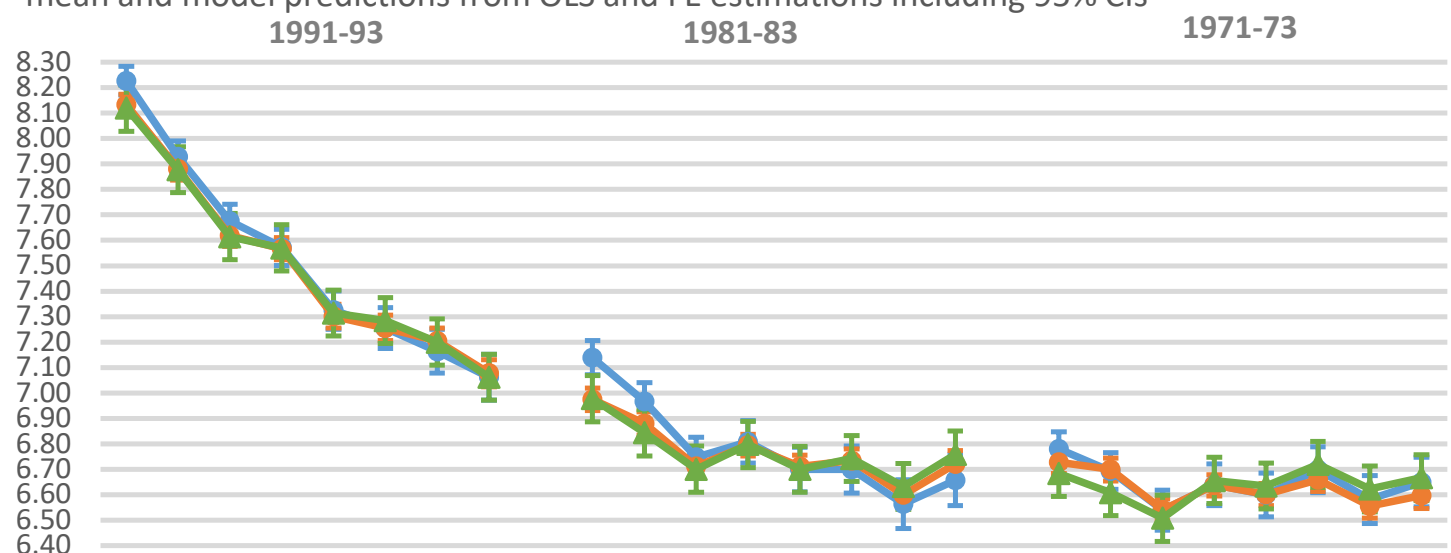

6.40
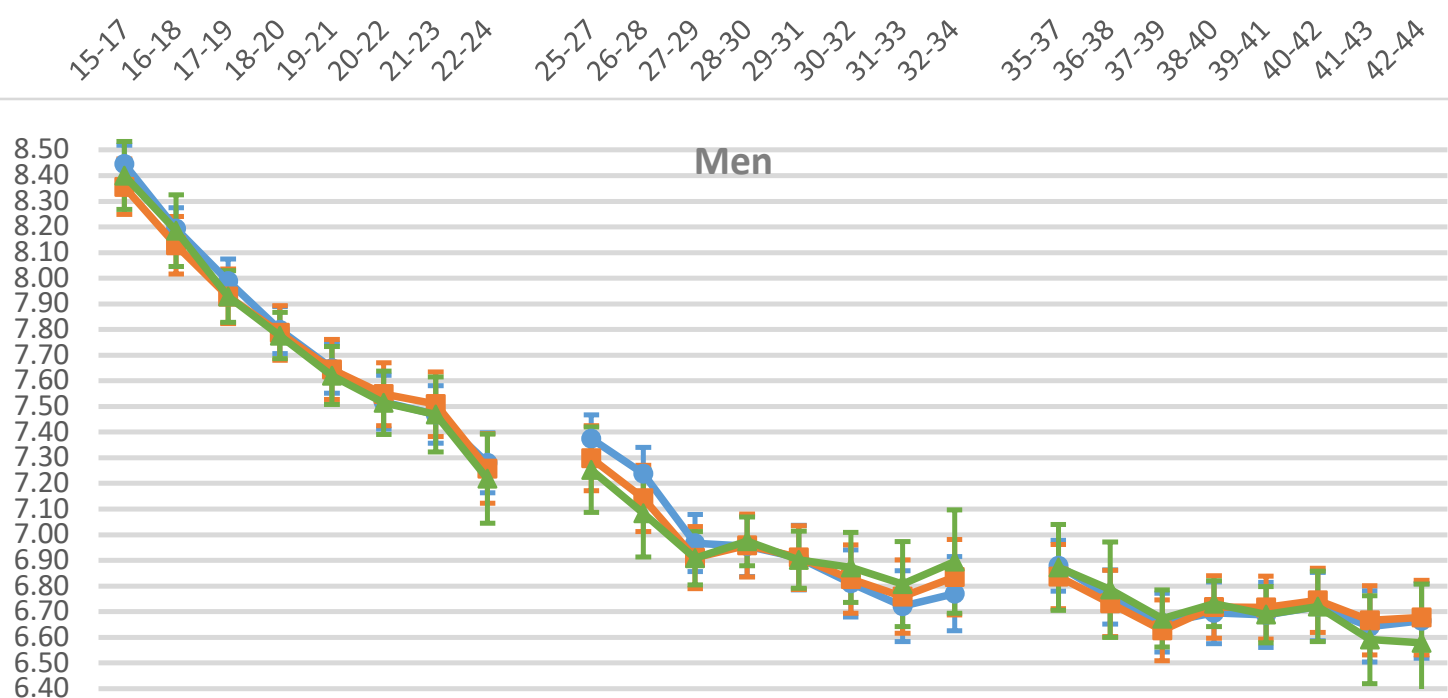

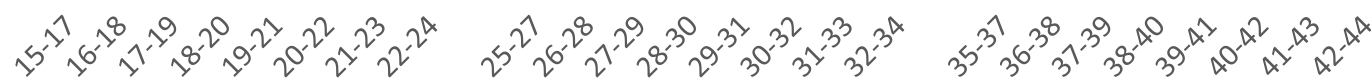

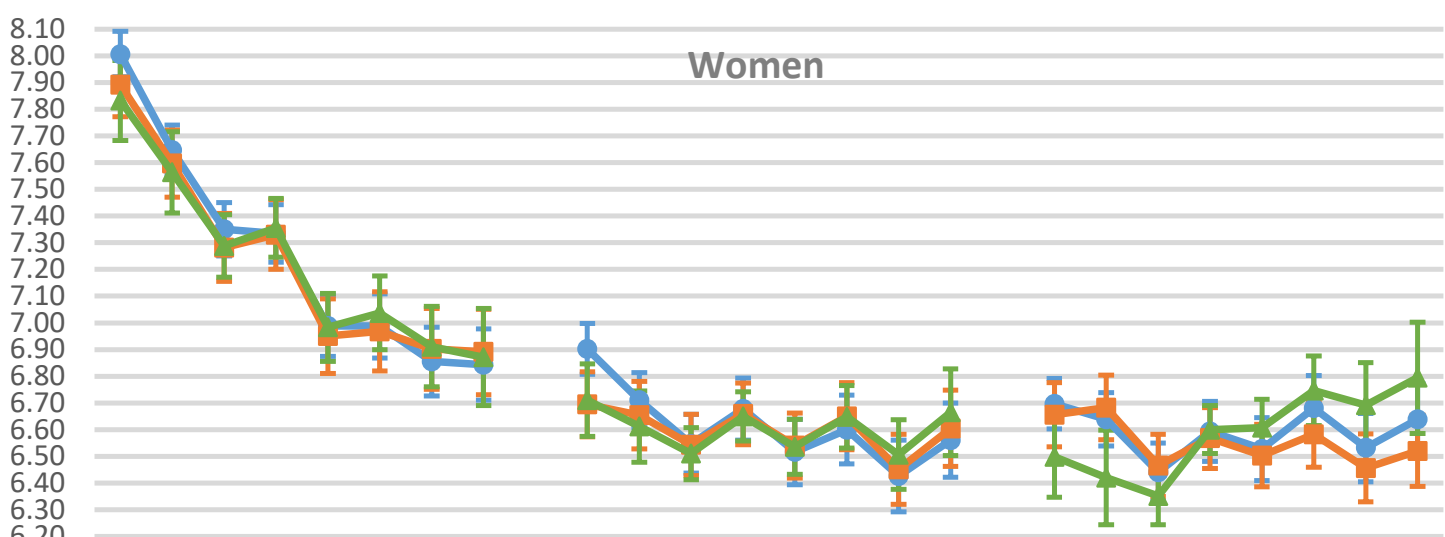

6.20

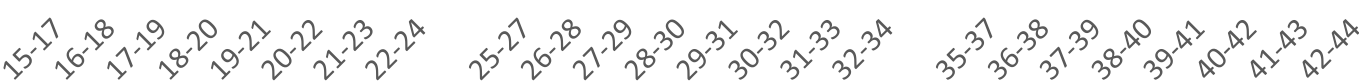

$$
\begin{aligned}
& \longrightarrow \text { Mean }- \text { OLS } \rightarrow \mathrm{FE}
\end{aligned}
$$

Note: Model predictions include marital status, number of children, self-rated health, employment status (being unemployed, not in the labour force), the natural logarithm of equivalised net household income, whether another person was present during interview, GDP per capita, and unemployment rate as control variables. Full sample (men and women) consists of 21,857, 20,826, 22,581 (unconditional mean) and 14,671, 17,864, 19,879 (OLS and FE predictions) observations for the three birth cohorts, respectively. 
Figure 4. Satisfaction with friends, social contacts, unconditional mean and model predictions from OLS and FE estimations including $95 \% \mathrm{Cls}$

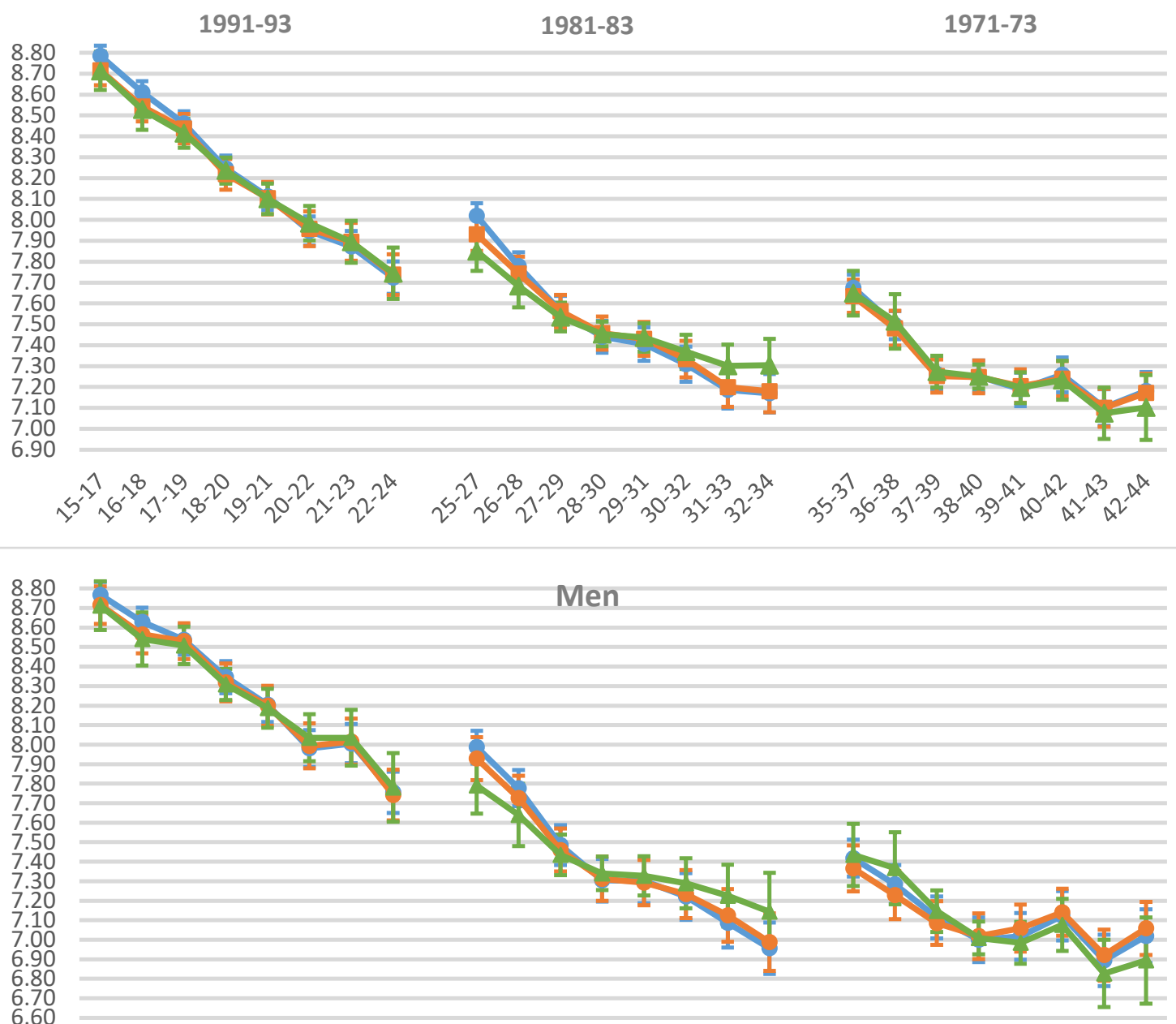

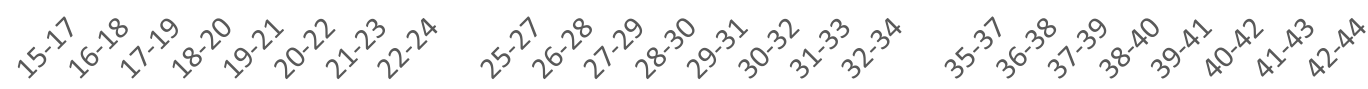

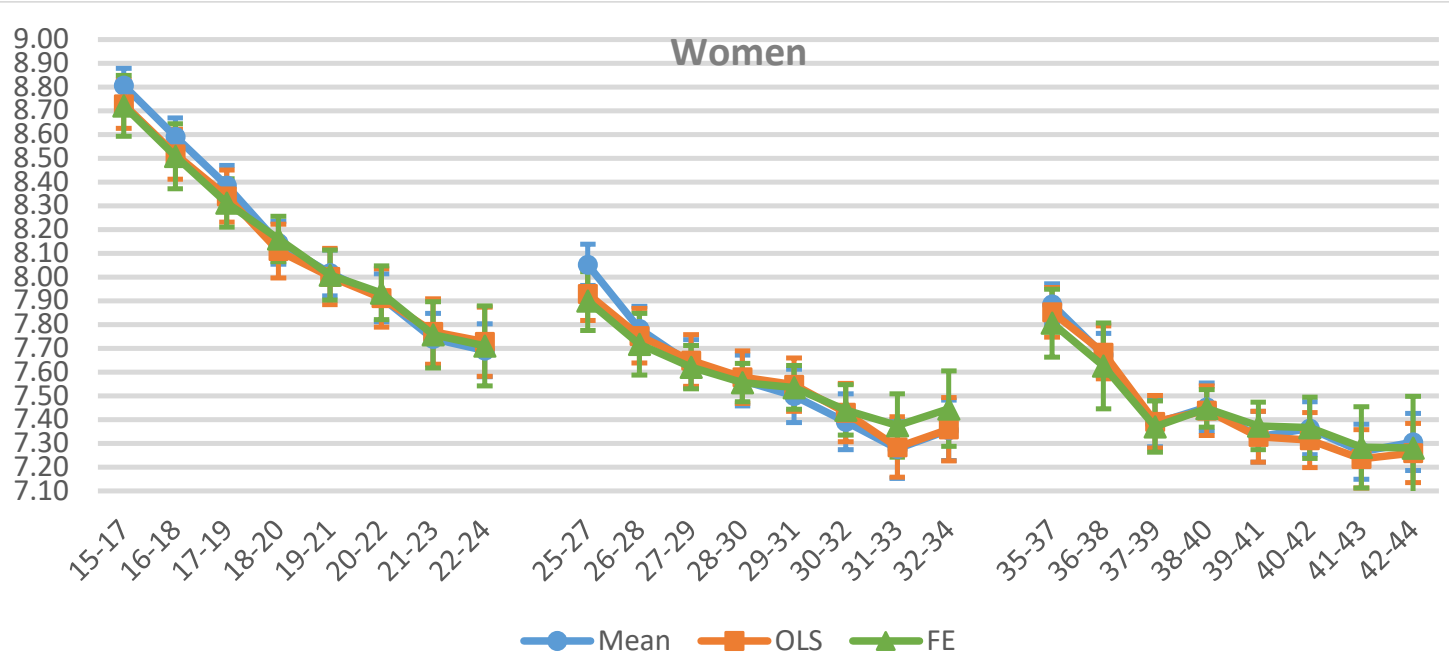

Note: Model predictions include marital status, number of children, self-rated health, employment status (being unemployed, not in the labour force), the natural logarithm of equivalized net household income, whether another person was present during interview, GDP per capita, and unemployment rate as control variables. Full sample (men and women) consists of 21,862, 20,831, 22,585 (unconditional mean) and 14,675, 17,863, 19,880 (OLS and FE predictions) observations for the three birth cohorts, respectively. 
Figure 5 then graphs the results for satisfaction with family life, which exhibits a marked downward trend within each cohort. The differences in unconditional means and fixed-effects predictions between the first wave of the young cohort and the eighth wave of the old cohort are 0.59 and 0.43 points, respectively, signalling a sharp and significant decrease as midlife approaches. Particularly strong and significant cohort effects are also observable between the middle and old cohort, about 0.35 and 0.44 points for the unconditional means and the fixed-effects predictions, respectively. This general pattern of declining satisfaction with family life is very similar for both men and women; however, the cohort effects differ: the female sample is characterised by a large and significant cohort effect between the young and middle cohorts but the male sample, by a large and significant effect between the middle and old cohort. As with social contacts and friends, assessments of family life are more favourable among the two older cohorts.

\section{Some methodological concern}

Potential concerns in our analysis could be (i) non-random response; (ii) attrition; and (iii) panel conditioning. First, as shown in table 1 , item nonresponse could be an issue particularly with respect to household income. However, it is not uncommon that respondents do not want to reveal their income and non-response rates of about $20 \%$ are quite common (Sousa-Poza \& Henneberger, 2000). Missing information on household income is an even more severe problem in the youngest cohort because respondents at the age of around 15+ years are likely to live with their parents and probably have no information about parents' and household income. As a check of whether missing information biases to our results, we re-estimate our OLS and fixed-effects regressions without the household income variable. The predictions of these regressions do not differ in any notable way from our main specification.

Second, the continuous decline in sample size could raise concerns regarding panel attrition. However, it is important to note that more than $50 \%$ of our regression samples are included in all waves. As a robustness check, we use a balanced panel and demonstrate that the unconditional mean and model predictions from a balanced versus an unbalanced panel slightly differ in levels but not in trends. In addition, following Wooden and $\mathrm{Li}$ (2014) we include a variable indicating whether a respondent does not participate in wave $t+1$ to test and control for potential selectivity bias (see also Verbeek \& Nijman (1992)). Re-estimating our regressions including this variable does not notably change our results.

Third, some of the patterns produced in this study could be influenced by panel conditioning effects, i.e. the possibility that the duration a person spends in a panel affects the way the person responds to certain questions. Wooden and $\mathrm{Li}$ (2014), using Australian HILDA data, find very little evidence that average life satisfaction is affected by the duration of individual stays in the panel. Likewise, in their analysis of the big five personality traits using the SOEP, Lucas and Donnellan (2011) show that panel conditioning effects are present but small in size. However, Kassenboehmer and Haisken-DeNew (2012) demonstrate that time in the panel effects are more pronounced among German SOEP respondents (see also Baird, Lucas, \& Donnellan, 2010). The usual way to analyse this effect is with refreshment samples (e.g. Baird et al, 2010; Lucas \& Donnellan, 2011; Wooden \& Li, 2014). Unfortunately, the cohort design of pairfam has no refreshments and it is thus not possible to assess panel conditioning effects in a comprehensive way. Past research has shown that, if panel conditioning effects exist, they are small and always negative, i.e. life satisfaction declines with the duration in the panel. Baird et al. (2010), for example, show that, on a 10-point life satisfaction scale, with each additional year in the SOEP survey, life satisfaction scores decline by only about .03 points. In order to get a rough indication of whether our results are being influenced by panel conditioning, we run our OLS estimates and include a variable describing the length of time that a respondent stays in the panel. Although we do not have a refreshment sample, not all respondents participated in all waves, i.e. some respondents interrupted their participation. Of the 52.427 observations in the regression sample on life satisfaction, about $43 \%$ missed out at least one wave. The results of these regressions do not change the conclusions of this paper. ${ }^{3}$ 
Figure 5. Satisfaction with family, unconditional mean and model predictions from OLS and FE estimations including $95 \% \mathrm{Cls}$

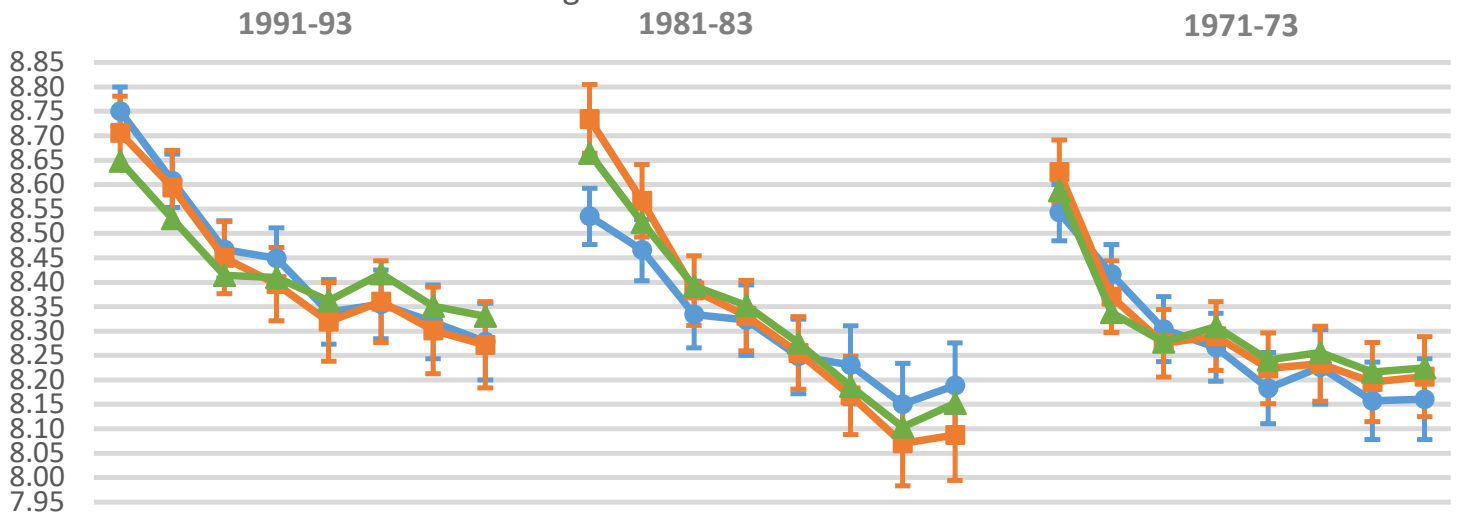

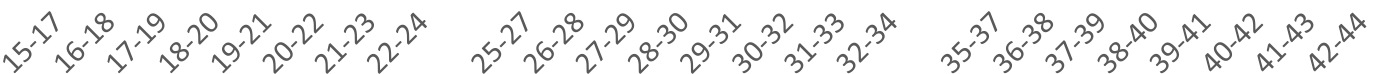

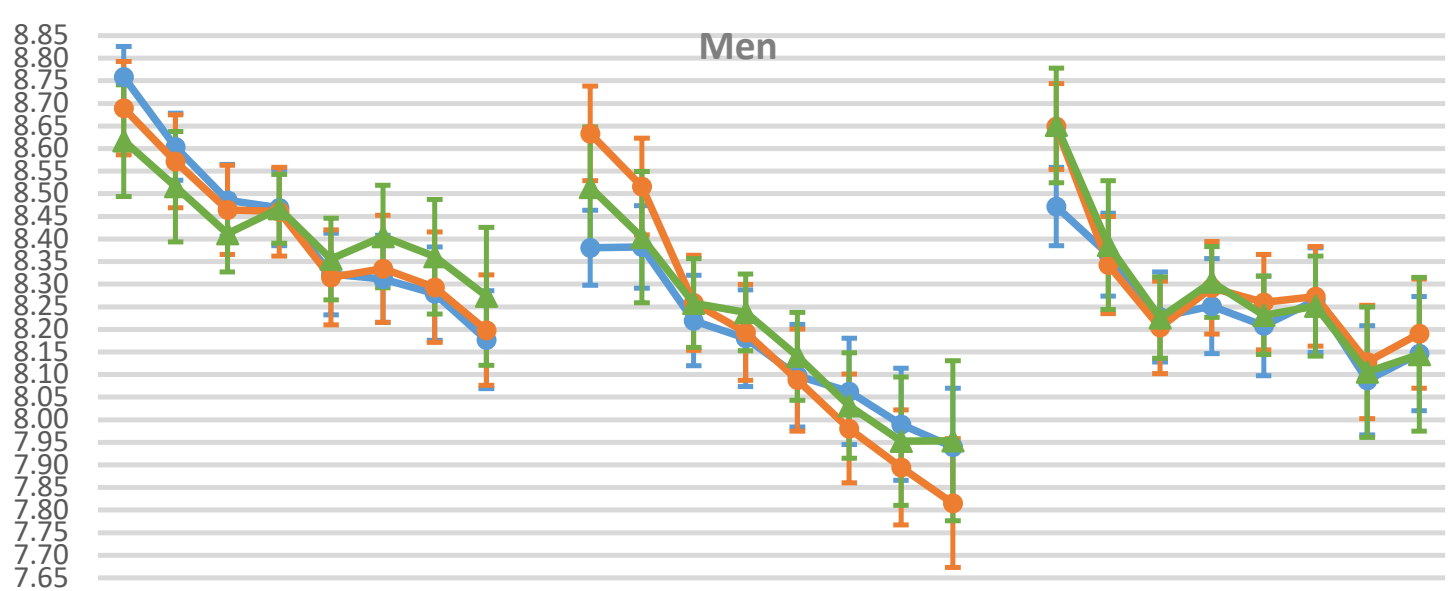

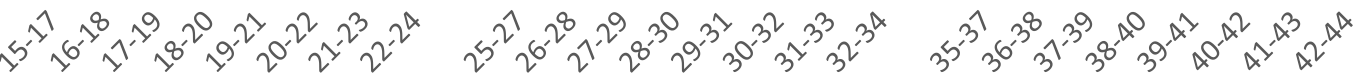

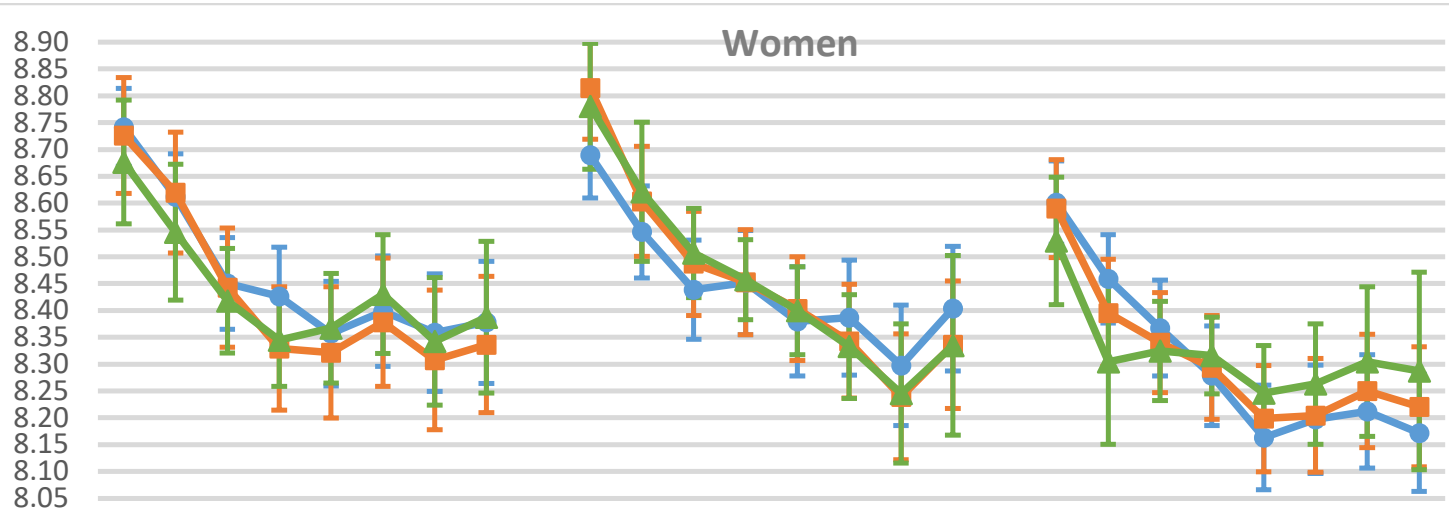

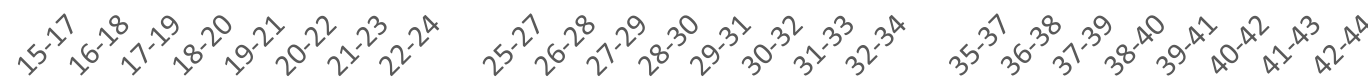

$\longrightarrow$ Mean $-\mathrm{OLS} \longrightarrow \mathrm{FE}$

Note: Model predictions include marital status, number of children, self-rated health, employment status (being unemployed, not in the labour force), the natural logarithm of equivalised net household income, whether another person was present during interview, GDP per capita, and unemployment rate as control variables. Full sample (men and women) consists of 21,860, 20,824, 22,570 (unconditional mean) and 14,674, 17,862, 19,868 (OLS and FE predictions) observations for the three birth cohorts, respectively. 


\section{Discussion and conclusions}

Using data from three cohorts born 10 years apart and applying three different but related analytical methods, this study provides evidence that SWB decreases from the late teens to about middle age. This decline is very pronounced for certain SWB domains, notably satisfaction with social contacts and friends, and satisfaction with leisure activities, hobbies and interests. There is also a downward trend in general life satisfaction. One of our most important findings is that the largest declines take place in the youngest cohort between the ages of 15 and 23. Although we are unaware of studies that document such changes in life satisfaction among young adults ${ }^{4}$, Goldbeck, Schmitz, Besier, Herschbach, and Henrich (2007) do provide evidence of a relatively large decline in life satisfaction among German adolescents aged 11 to 16. As a result, they argue that decreasing life satisfaction has to be considered as a developmental phenomenon. Our results indicate that these developmental changes among adolescents, which are also recorded for other countries (Proctor, Linley, \& Maltby, 2009), continue into young adulthood. They thus support the notion that 'emerging adulthood', the transitional developmental stage between late adolescence and adulthood that occurs between ages 18 and 24 (Arnett, 2004) is a stress-arousing and anxiety-provoking period because of the many diverse tasks and expectations it entails.

What could be causing the large drop in life satisfaction in the youngest cohort? In order to shed some light on this question we decomposed the difference in life satisfaction between the eighth and first survey years using a standard Oaxaca-Blinder decomposition (Blinder, 1973; Oaxaca, 1973). We try to explain the drop in life satisfaction by nesting the four domains into the analysis. Our results ${ }^{5}$ show that about $99 \%$ of the decline in life satisfaction can be explained by these four domains in this young cohort. Of the four domains, satisfaction with friends and satisfaction with leisure are equally influential and account for $85 \%$ of the decline in life satisfaction. Satisfaction with family plays a relatively less significant role, and job satisfaction has an attenuating effect, i.e. actually increases life satisfaction. Taken at face value, these results point to the important role that changing social structures and time allocation (e.g. most notably available time for leisure activities) have in shaping the wellbeing of young adults.

The advantage of using cohort data such as ours is the ability to directly control (i.e. observe) cohort effects. Perhaps the most striking result in our study is the size of these cohort effects; that is, the difference in reported SWB of similarly aged individuals in different cohorts. For example, the unconditional mean and the conditional mean of general life satisfaction from the fixed-effects model (i.e. once numerous socio-demographic factors, macro-level variables, and unobserved fixed-effects are controlled) among individuals aged 22-24 in the youngest cohort is 0.17 points higher than that of individuals aged 25-27 in the middle cohort. This discrepancy points to stark inter-cohort differences in SWB response behaviour. What is particularly intriguing is that these cohort effects arise even though the cohorts are only a decade apart. Their identification thus highlights the necessity of adequately controlling for cohort effects during any analysis of multi-cohort SWB data. It is also worth noting that not all domains exhibit an equally strong cohort effect. For instance, differences among cohorts in the satisfaction with family life domain is particularly striking, with older cohorts (ceteris paribus) having higher levels of satisfaction. This apparent increased dissatisfaction in the young cohort may have implications for the claim that the rise in non-traditional attitudes towards family, as well as an increased belief in gender egalitarianism, could be negatively affecting satisfaction with family life (Lye \& Biblarz, 1993; Taniguchi \& Kaufman, 2013).

Admittedly, it could be argued that comparing the eighth wave with the first wave of an adjacent cohort fails to take into account that data collection occurred in different years. However, although this point is valid, our controls for annual GDP and unemployment may well capture much of the time effect. It is also highly unlikely that further timedependent variables can explain some of the extremely large (and even gender and domainspecific) differences between cohorts.

It should also be noted that most studies based on long-running panel data (e.g. the BHPS or SOEP) can only indirectly or inadequately control for cohort effects, primarily because of the small size of the (narrowly defined) cohorts and their relatively short duration in the panel. For example, in a comparable research setting (i.e. survey years 
between 2008 and 2015) using the SOEP, the average sample size for individuals born 1971-1973 with no missing values of overall life satisfaction is a mere 823 per survey year, with an average panel duration of 4.8 years.
No doubt as further waves of pairfam are collected, a more precise analysis of individual cohort SWB trajectories will become possible and shed more light on how SWB evolves across time and generations.

\section{Acknowledgements}

This paper uses data from the German Family Panel pairfam, coordinated by Josef Brüderl, Karsten Hank, Johannes Huinink, Bernhard Nauck, Franz Neyer and Sabine Walper. pairfam is funded as long-term project by the German Research Foundation (DFG).

\section{References}

Argyle, M. (2001). The psychology of happiness. London: Routledge.

Arnett, J. (2004). Emerging adulthood: The winding road from the late teens through the twenties. New York: Oxford University Press.

Baetschmann, G. (2014). Heterogeneity in the relationship between happiness and age: evidence from the German Socio-Economic panel. German Economic Review, 15(3), 393-410. https://doi.org/10.1111/geer.12015

Baird, B. M., Lucas, R. E., \& Donnellan, M. B. (2010). Life Satisfaction Across the Lifespan: Findings from Two Nationally Representative Panel Studies. Social Indicators Research, 99(2), 183-203. https://doi.org/10.1007/s11205-010-9584-9

Bauer, J. M., Cords, D., Sellung, R., \& Sousa-Poza, A. (2015). Effects of different life events on life satisfaction in the Russian Longitudinal Monitoring Survey. Economics Letters, 129, 91-94. https://doi.org/10.1016/j.econlet.2015.02.016

Blanchflower, D. G. \& Oswald, A. J. (2008). Is well-being U-shaped over the life cycle? Social Science \& Medicine, 66, 1733-1749. https://doi.org/10.1016/j.socscimed.2008.01.030

Blinder, A. S. (1973). Wage discrimination: Reduced form and structural estimates. Journal of Human Resources, 8, 436-455. https://doi.org/10.2307/144855

Brickman, P., Coates, D., \& Janoff-Bulman, R. (1978). Lottery winners and accident victims: Is happiness relative? Journal of Personality and Social Psychology, 36(8), 917-927. https://doi.org/10.1037/0022-3514.36.8.917

Brim, O. G. (1992). Ambition: how we manage success and failure throughout our lives. New York: Basic Books.

Brüderl, J., Hank, K., Huinink, J., Nauck, B., Neyer, F. J., Walper, S., ... Wilhelm, B. (2017). The German Family Panel (pairfam). GESIS Data Archive, Cologne. ZA5678 Data file Version 8.0.0, https://doi.org/10.4232/pairfam.5678.8.0.0

Charles, S. \& Carstensen, L. (2009). Socioemotional selectivity theory. In H. Reis \& S. Sprecher (Eds.), Encyclopedia of human relationships (pp. 1578-1581). Thousand Oaks: Sage Publications. https://doi.org/10.4135/9781412958479.n519

Cheng, T. C., Powdthavee, N., \& Oswald, A. J. (2017). Longitudinal Evidence for a Midlife Nadir in Human Well-being: Results from Four Data Sets. Economic Journal, 127(599), 126-142. https://doi.org/10.1111/ecoj.12256

Chiriboga, D. A. (1997). Crisis, challenge, and stability in the middle years. In M. E. Lachman \& J. B. James (Eds.), Multiple paths of midlife development (pp. 293-322). Chicago: University of Chicago Press.

Clark, A. (2007). Born to be mild? Cohort effects don't (fully) explain why well-being is U-shaped in age. IZA Discussion paper No. 3170.

Clark, A. \& Georgellis, Y. (2012). Back to Baseline in Britain: Adaptation in the British Household Panel Survey. Economica, 80, 496-512. https://doi.org/10.1111/ecca.12007 
Clark, A. \& Oswald, A. (1994). Unhappiness and unemployment. Economic Journal, 104(424), 648-659. https://doi.org/10.2307/2234639

Diener, E., \& Lucas, R. E. (1999). Personality and subjective well-being. In D. Kahneman, E. Schwarz, \& N. Diener (Eds.), Well-being: The foundations of hedonic psychology (pp. 213-229). New York: Russell Sage.

Diener, E., Emmons, R. A., Larsen, R. J., \& Griffin, S. (1985). The Satisfaction With Life Scale. Journal of Personality Assessment, 49(1), 71-75. https://doi.org/10.1207/s15327752jpa4901 13

Easterlin, R. A. (2006). Life cycle happiness and its sources: Intersections of psychology, economics, and demography. Journal of Economic Psychology, 27(4), 463-482. https://doi.org/10.1016/i.joep.2006.05.002

Easterlin, R. A. \& Sawangfa, O. (2007). Happiness and domain satisfaction: theory and evidence. IZA Discussion Paper No. 2584, 2007: 1-35.

Ferrer-i-Carbonell, A. \& Frijters, P. (2004). How Important is methodology for the estimates of the determinants of happiness? Economic Journal, 114(497), 641-659. https://doi.org/10.1111/i.14680297.2004.00235.x

Frijters, P. \& Beatton, T. (2012). The mystery of the U-shaped relationship between happiness an age. Journal of Economic Behavior \& Organization, 82, 525-542. https://doi.org/10.1016/i.jebo.2012.03.008

Galambos, N. L., Fang, S., Krahn, H. J., Johnson, M. D., \& Lachman, M. E. (2015). Up, not down: The age curve in happiness from early adulthood to midlife in two longitudinal studies. Developmental Psychology, 51(11), 1664-1671. https://doi.org/10.1037/dev0000052

Glenn, N. (2009). Is the apparent U-shape of well-being over the life course a result of inappropriate use of control variables? A commentary on Blanchflower and Oswald. Social Science \& Medicine, 69, 481485. https://doi.org/10.1016/j.socscimed.2009.05.038

Goldbeck, L., Schmitz, T. G., Besier, T., Herschbach, P., \& Henrich, G. (2007). Life satisfaction decreases during adolescence. Quality of Life Research, 16, 969-979. https://doi.org/10.1007/s11136-007$\underline{9205-5}$

Gwozdz, W. and Sousa-Poza, A. (2010). Ageing, health and life satisfaction for the oldest old: an analysis for Germany. Social Indicators Research, 97, 397-417. https://doi.org/10.1007/s11205-009-9508-8

Hellevik, O. (2017). The U-shaped age-happiness relationship: real or methodological artifact? Quality and Quantity, 51, 177-197. https://doi.org/10.1007/s11135-015-0300-3

Howell, R. T., Kern, M. L., \& Lyubomirsky, S. (2007). Health benefits: Meta-analytically determining the impact of well-being on objective health outcomes. Health Psychology Review, 1, 83-136. https://doi.org/10.1080/17437190701492486

Huinink, J., Brüderl, J. Nauck, B., Walper, Castiglioni, L., \& Feldhaus, M. (2011). Panel analysis of intimate relationships and family dynamics (pairfam): Conceptual framework and design. Zeitschrift für Familienforschung - Journal of Family Research, 23, 77-101.

Jaques, E. (1965). Death and the midlife crisis. International Journal of Psychoanalysis, 46, 502-514.

Jovanovic, V. (2016). The validity of the Satisfaction with Life Scale in adolescents and a comparison with single-item life satisfaction measures: a preliminary study. Quality of Life Research, 25, 3173-3180. https://doi.org/10.1007/s11136-016-1331-5

Kassenboehmer, S. C. \& Haisken-DeNew, J. P. (2012). Heresy or enlightment? The well-being age U-shape effect is flat. Economics Letters, 117, 235-238. https://doi.org/10.1016/i.econlet.2012.05.013

Lang, I.A., Llewellyn, D.J., Hubbard, R.E., Langa, K.M., \& Melzer, D. (2011). Income and the midlife peak in common mental disorder prevalence. Psychological Medicine, 41(7), 1365-1372. https://doi.org/10.1017/S0033291710002060

Levinson, D. J. \& Levinson, J. D. (1996). The seasons of a woman's life. New York: Knopf.

$\mathrm{Li}, \mathrm{N}$. (2016). Multidimensionality of longitudinal data: Unlocking the age-happiness puzzle. Social Indicators Research, 128(1), 305-320. https://doi.org/10.1007/s11205-015-1032-4 
López Ulloa, B. F., Møller, V., \& Sousa-Poza, A. (2013). How does subjective well-being evolve with age? A literature review. Journal of Population Ageing, 6(3), 227-246. https://doi.org/10.1007/s12062-013$\underline{9085-0}$

Lucas, R. E. (2007). Adaptation and the set point model of subjective well-being. Current Directions in Psychological Science, 16(2), 75-79. https://doi.org/10.1111/j.1467-8721.2007.00479.x

Lucas, R. E. \& Donnellan, B. M. (2011). Personality development across the life span: Longitudinal analyses with a national sample from Germany. Journal of Personality and Social Psychology, 101(4), 847-861. https://doi.org/10.1037/a0024298

Lye, D. N. \& Biblarz, T. J. (1993). The effects of attitudes toward family life and gender roles on marital satisfaction. Journal of Family Issues, 14(2), 157-188. https://doi.org/10.1177/019251393014002002

McAdams, K. K., Lucas, R. E., \& Donnellan, B. M. (2012). The role of domain satisfaction in explaining the paradoxical association between life satisfaction and age. Social Indicators Research, 109, 295-303. https://doi.org/10.1007/s11205-011-9903-9

McCrae, R. \& Costa, P. (1990). Personality in adulthood. New York: Guilford. https://doi.org/10.1007/s11205$\underline{011-9903-9}$

Modigliani, F., \& Brumberg, R. (1954). Utility analysis and the consumption function: an interpretation of cross-section data. In K. Kurihara (Ed.), Post-Keynesian Economics. New Brunswick: Rutgers University Press.

Oaxaca, R. (1973). Male-female wage differentials in urban labor markets. International Economic Review, 14, 693-709. https://doi.org/10.2307/2525981

Proctor, C. L., Linley, A. \& Maltby, J. (2009). Youth life satisfaction: A review of the literature. Journal of Happiness Studies, 10, 583-630. https://doi.org/10.1007/s10902-008-9110-9

Robustelli, B. L. \& Whisman, M. A. (2016). Gratitude and Life Satisfaction in the United States and Japan. Journal of Happiness Studies, 19(1), 41-55. https://doi.org/10.1007/s10902-016-9802-5

Schilling, O. K. (2005). Cohort- and age-related decline in elder's life satisfaction: is there really a paradox? European Journal of Ageing, 2(4), 254-263. https://doi.org/10.1007/s10433-005-0016-7

Sousa-Poza, A. \& Henneberger, F. (2000). Wage Data Collected by Telephone Interviews: An Empirical Analysis of the Item Nonresponse Problem and its Implications for the Estimation of Wage Functions. Swiss Journal of Economics and Statistics, 136(1), 79-98.

Taniguchi, H. \& Kaufman, G. (2013). Gender role attitudes, troubles talk, and marital satisfaction in Japan. Journal of Social and Personal Relationships, 31, 7975-7994.

Theuns, P., Baran, B., van Vaerenbergh, R., Hellenbosch, G., \& Tiliouine, H. (2012). A cross-cultural experimental approach to the contribution of health, religion and personal relations to subjective satisfaction with life as a whole. Psicológica, 33, 591-608.

Theuns, P., Hofmans, J., \& Verresen N. (2007). A functional measurement inquiry on the contribution of different life domains to overall subjective well-being. Teori \& Modelli, n.s., XII, 1-2, 181-189.

Van Landeghem, B. (2008). Human well-being over the life cycle: longitudinal evidence from a 20-year panel. LICOS Discussion Paper No. 213/2008, Katholieke Universiteit Leuven, 2008. https://doi.org/10.2139/ssrn.1360731

Van Landeghem, B. (2012). A test for convexity of human well-being over the lifecycle: longitudinal evidence from a 20-year panel. Journal of Economic Behavior and Organization, 81(2), 571-585. https://doi.org/10.1016/i.jebo.2011.08.001

Veenhoven, R. (2008). Healthy happiness: effects of happiness on physical health and the consequences for preventive health care. Journal of Happiness Studies, 9, 449-469. https://doi.org/10.1007/s10902006-9042-1

Verbeek, M., \& Nijman, T. (1992). Testing for selectivity bias in panel data models. International Economic Review, 33(3), 681-703. https://doi.org/10.2307/2527133

Weiss, A., King, J. E., Inoue-Murayama, M., Matsuzawa, T., \& Oswald, A. J. (2012). Evidence for a midlife crisis in great apes consistent with the U-shape in human well-being. Proceedings of the National Academy of Sciences, 109(49), 19949-19952. https://doi.org/10.1073/pnas.1212592109 
Wethington, E. (2000). Expecting Stress: Americans and the "Midlife Crisis". Motivation and Emotion, 24(2), 85-103. https://doi.org/10.1023/A:1005611230993

Wooden, M. \& Li, N. (2014). Panel conditioning and subjective well-being. Social Indicators Research, 117, 235-255. https://doi.org/10.1007/s11205-013-0348-1

\section{Endnotes}

1. Wethington (2000) does, however, point out that this high prevalence is partly due to respondents' tendency to use the term 'midlife crisis' quite broadly and to encompass events that occurred any time between the ages of about 30 to 70 . Quoting Wethington (2000, p. 99): "It also implies a parsimonious explanation for why beliefs that the midlife crisis is a common risk of aging are so persistent. Almost any event or feeling socially symbolic of aging can qualify as a midlife crisis, if the definition is very elastic."

2. A detailed description of this study can be found in Huinink et al. (2011).

3 . The results of these robustness tests are available upon request.

4. Interestingly, Galambos et al. (2015) in their longitudinal study actually observe an increase in happiness during young adulthood. Two points, however, must be stressed when comparing this study with ours. First, Galambos et al. (2015) follow a small group of individuals from workingand middle-class neighborhoods in a large western city in Canada, i.e. their sample cannot be compared with ours. Second, and importantly, they collect happiness data with a three-point scale, which does not allow for much variability in responses.

5. Available upon request. 


\section{Appendix}

Table A.1. Overall life satisfaction, unconditional mean and model predictions from OLS and FE estimations including standard errors

\begin{tabular}{|c|c|c|c|c|c|c|c|c|c|c|c|c|c|c|c|c|c|c|}
\hline \multirow[b]{3}{*}{ Cohort 1991-93 } & \multicolumn{6}{|c|}{ Full sample } & \multicolumn{6}{|c|}{ Men } & \multicolumn{6}{|c|}{ Women } \\
\hline & \multicolumn{2}{|c|}{ Mean } & \multicolumn{2}{|c|}{ OLS } & \multicolumn{2}{|l|}{ FE } & \multicolumn{2}{|c|}{ Mean } & \multicolumn{2}{|l|}{ OLS } & \multicolumn{2}{|l|}{$\mathrm{FE}$} & \multicolumn{2}{|c|}{ Mean } & \multicolumn{2}{|c|}{ OLS } & \multicolumn{2}{|l|}{ FE } \\
\hline & Margin & SE & Margin & SE & Margin & SE & Margin & SE & Margin & SE & Margin & SE & Margin & SE & Margin & SE & Margin & SE \\
\hline $15-17$ & 7.95 & 0.02 & 7.87 & 0.04 & 7.78 & 0.04 & 8.05 & 0.03 & 7.96 & 0.05 & 7.90 & 0.06 & 7.84 & 0.03 & 7.76 & 0.05 & 7.65 & 0.05 \\
\hline $16-18$ & 8.05 & 0.03 & 8.00 & 0.03 & 7.92 & 0.04 & 8.12 & 0.03 & 8.07 & 0.05 & 8.00 & 0.06 & 7.98 & 0.04 & 7.94 & 0.05 & 7.84 & 0.05 \\
\hline 17-19 & 7.83 & 0.03 & 7.81 & 0.03 & 7.75 & 0.03 & 7.95 & 0.04 & 7.91 & 0.04 & 7.87 & 0.04 & 7.70 & 0.04 & 7.70 & 0.05 & 7.63 & 0.04 \\
\hline $18-20$ & 7.74 & 0.03 & 7.70 & 0.03 & 7.72 & 0.03 & 7.83 & 0.04 & 7.76 & 0.05 & 7.77 & 0.04 & 7.65 & 0.04 & 7.63 & 0.05 & 7.68 & 0.04 \\
\hline $19-21$ & 7.71 & 0.03 & 7.72 & 0.03 & 7.78 & 0.03 & 7.79 & 0.04 & 7.80 & 0.05 & 7.84 & 0.04 & 7.64 & 0.05 & 7.64 & 0.05 & 7.71 & 0.04 \\
\hline $20-22$ & 7.71 & 0.03 & 7.67 & 0.04 & 7.73 & 0.03 & 7.78 & 0.05 & 7.78 & 0.05 & 7.84 & 0.05 & 7.64 & 0.05 & 7.56 & 0.05 & 7.63 & 0.05 \\
\hline $21-23$ & 7.65 & 0.04 & 7.64 & 0.04 & 7.70 & 0.04 & 7.71 & 0.05 & 7.72 & 0.05 & 7.77 & 0.07 & 7.59 & 0.05 & 7.56 & 0.05 & 7.65 & 0.05 \\
\hline $22-24$ & 7.58 & 0.04 & 7.55 & 0.04 & 7.64 & 0.05 & 7.65 & 0.05 & 7.63 & 0.06 & 7.71 & 0.08 & 7.51 & 0.05 & 7.47 & 0.06 & 7.57 & 0.06 \\
\hline \multicolumn{19}{|c|}{ Cohort 1981-83 } \\
\hline $25-27$ & 7.41 & 0.03 & 7.51 & 0.03 & 7.47 & 0.04 & 7.31 & 0.04 & 7.52 & 0.05 & 7.46 & 0.06 & 7.50 & 0.04 & 7.51 & 0.05 & 7.47 & 0.06 \\
\hline $26-28$ & 7.44 & 0.03 & 7.61 & 0.03 & 7.55 & 0.04 & 7.36 & 0.04 & 7.57 & 0.05 & 7.52 & 0.06 & 7.52 & 0.04 & 7.63 & 0.05 & 7.57 & 0.06 \\
\hline $27-29$ & 7.43 & 0.03 & 7.52 & 0.03 & 7.49 & 0.03 & 7.40 & 0.05 & 7.51 & 0.05 & 7.48 & 0.04 & 7.47 & 0.04 & 7.53 & 0.04 & 7.50 & 0.04 \\
\hline $28-30$ & 7.44 & 0.03 & 7.47 & 0.03 & 7.47 & 0.03 & 7.35 & 0.05 & 7.40 & 0.05 & 7.39 & 0.04 & 7.52 & 0.05 & 7.54 & 0.04 & 7.54 & 0.03 \\
\hline 29-31 & 7.48 & 0.04 & 7.46 & 0.03 & 7.48 & 0.03 & 7.41 & 0.05 & 7.40 & 0.05 & 7.42 & 0.04 & 7.55 & 0.05 & 7.52 & 0.04 & 7.54 & 0.04 \\
\hline $30-32$ & 7.56 & 0.04 & 7.51 & 0.04 & 7.54 & 0.03 & 7.43 & 0.06 & 7.36 & 0.05 & 7.40 & 0.05 & 7.69 & 0.05 & 7.65 & 0.05 & 7.67 & 0.04 \\
\hline $31-33$ & 7.53 & 0.04 & 7.43 & 0.04 & 7.49 & 0.04 & 7.44 & 0.06 & 7.34 & 0.06 & 7.41 & 0.06 & 7.62 & 0.05 & 7.52 & 0.05 & 7.57 & 0.06 \\
\hline $32-34$ & 7.49 & 0.04 & 7.34 & 0.04 & 7.44 & 0.05 & 7.40 & 0.06 & 7.23 & 0.06 & 7.33 & 0.07 & 7.57 & 0.06 & 7.45 & 0.06 & 7.54 & 0.07 \\
\hline \multicolumn{19}{|c|}{ Cohort 1971-73 } \\
\hline $35-37$ & 7.48 & 0.03 & 7.48 & 0.03 & 7.48 & 0.04 & 7.43 & 0.04 & 7.51 & 0.04 & 7.52 & 0.06 & 7.52 & 0.04 & 7.44 & 0.04 & 7.44 & 0.06 \\
\hline $36-38$ & 7.48 & 0.03 & 7.57 & 0.03 & 7.57 & 0.05 & 7.37 & 0.04 & 7.48 & 0.05 & 7.53 & 0.07 & 7.57 & 0.04 & 7.63 & 0.04 & 7.60 & 0.07 \\
\hline $37-39$ & 7.39 & 0.03 & 7.42 & 0.03 & 7.45 & 0.03 & 7.32 & 0.05 & 7.39 & 0.04 & 7.43 & 0.04 & 7.45 & 0.04 & 7.46 & 0.04 & 7.47 & 0.04 \\
\hline $38-40$ & 7.31 & 0.03 & 7.34 & 0.03 & 7.34 & 0.03 & 7.22 & 0.05 & 7.29 & 0.05 & 7.28 & 0.04 & 7.37 & 0.05 & 7.40 & 0.04 & 7.40 & 0.03 \\
\hline 39-41 & 7.43 & 0.04 & 7.44 & 0.03 & 7.42 & 0.03 & 7.38 & 0.05 & 7.40 & 0.05 & 7.35 & 0.04 & 7.48 & 0.05 & 7.48 & 0.05 & 7.48 & 0.04 \\
\hline $40-42$ & 7.40 & 0.04 & 7.35 & 0.03 & 7.36 & 0.04 & 7.33 & 0.05 & 7.31 & 0.05 & 7.30 & 0.05 & 7.44 & 0.05 & 7.39 & 0.05 & 7.41 & 0.05 \\
\hline $41-43$ & 7.40 & 0.04 & 7.36 & 0.04 & 7.36 & 0.05 & 7.36 & 0.06 & 7.33 & 0.05 & 7.31 & 0.07 & 7.42 & 0.05 & 7.39 & 0.05 & 7.41 & 0.06 \\
\hline $42-44$ & 7.44 & 0.04 & 7.35 & 0.04 & 7.35 & 0.06 & 7.36 & 0.06 & 7.28 & 0.06 & 7.24 & 0.09 & 7.50 & 0.05 & 7.43 & 0.05 & 7.44 & 0.08 \\
\hline
\end{tabular}




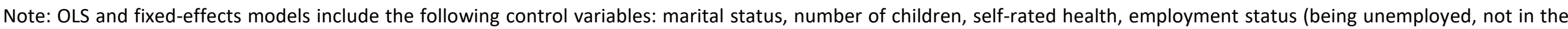
labour force), the natural logarithm of equivalized net household income, whether another person was present during the interview, GDP per capita, and unemployment rate. 
Table A.2. Satisfaction with school, education, career, unconditional mean and model predictions from OLS and FE estimations including standard errors

\begin{tabular}{|c|c|c|c|c|c|c|c|c|c|c|c|c|c|c|c|c|c|c|}
\hline & \multicolumn{6}{|c|}{ Full sample } & \multicolumn{6}{|c|}{ Men } & \multicolumn{6}{|c|}{ Women } \\
\hline & \multicolumn{2}{|c|}{ Mean } & \multicolumn{2}{|c|}{ OLS } & \multicolumn{2}{|l|}{ FE } & \multicolumn{2}{|c|}{ Mean } & \multicolumn{2}{|c|}{ OLS } & \multicolumn{2}{|l|}{$\mathrm{FE}$} & \multicolumn{2}{|c|}{ Mean } & \multicolumn{2}{|c|}{ OLS } & \multicolumn{2}{|l|}{ FE } \\
\hline & Margin & SE & Margin & SE & Margin & SE & Margin & SE & Margin & SE & Margin & SE & Margin & SE & Margin & SE & Margin & SE \\
\hline \multicolumn{19}{|c|}{ Cohort 1991-93 } \\
\hline $15-17$ & 7.36 & 0.03 & 7.34 & 0.04 & 7.25 & 0.05 & 7.37 & 0.04 & 7.37 & 0.06 & 7.33 & 0.08 & 7.35 & 0.04 & 7.30 & 0.06 & 7.19 & 0.08 \\
\hline $16-18$ & 7.35 & 0.03 & 7.35 & 0.05 & 7.26 & 0.06 & 7.42 & 0.05 & 7.45 & 0.06 & 7.40 & 0.09 & 7.28 & 0.05 & 7.24 & 0.07 & 7.14 & 0.08 \\
\hline 17-19 & 7.37 & 0.04 & 7.36 & 0.04 & 7.36 & 0.04 & 7.46 & 0.05 & 7.40 & 0.06 & 7.44 & 0.06 & 7.28 & 0.05 & 7.31 & 0.07 & 7.29 & 0.06 \\
\hline $18-20$ & 7.50 & 0.04 & 7.45 & 0.05 & 7.51 & 0.04 & 7.56 & 0.05 & 7.48 & 0.06 & 7.53 & 0.05 & 7.44 & 0.06 & 7.41 & 0.07 & 7.48 & 0.06 \\
\hline $19-21$ & 7.51 & 0.04 & 7.48 & 0.05 & 7.54 & 0.05 & 7.59 & 0.06 & 7.60 & 0.06 & 7.62 & 0.06 & 7.42 & 0.06 & 7.35 & 0.07 & 7.43 & 0.07 \\
\hline $20-22$ & 7.49 & 0.04 & 7.42 & 0.05 & 7.48 & 0.05 & 7.53 & 0.06 & 7.52 & 0.07 & 7.54 & 0.08 & 7.45 & 0.06 & 7.33 & 0.07 & 7.41 & 0.07 \\
\hline $21-23$ & 7.48 & 0.05 & 7.52 & 0.05 & 7.55 & 0.06 & 7.57 & 0.06 & 7.63 & 0.07 & 7.61 & 0.09 & 7.40 & 0.07 & 7.41 & 0.07 & 7.46 & 0.08 \\
\hline $22-24$ & 7.50 & 0.05 & 7.45 & 0.05 & 7.49 & 0.07 & 7.60 & 0.07 & 7.54 & 0.07 & 7.55 & 0.11 & 7.39 & 0.07 & 7.35 & 0.08 & 7.39 & 0.09 \\
\hline \multicolumn{19}{|c|}{ Cohort 1981-83 } \\
\hline $25-27$ & 7.14 & 0.04 & 7.13 & 0.05 & 7.08 & 0.06 & 7.13 & 0.05 & 7.24 & 0.06 & 7.18 & 0.08 & 7.14 & 0.05 & 7.03 & 0.06 & 6.99 & 0.08 \\
\hline $26-28$ & 6.99 & 0.04 & 7.10 & 0.04 & 7.03 & 0.06 & 7.01 & 0.05 & 7.20 & 0.06 & 7.14 & 0.08 & 6.98 & 0.06 & 7.01 & 0.06 & 6.92 & 0.08 \\
\hline $27-29$ & 7.09 & 0.04 & 7.13 & 0.04 & 7.12 & 0.04 & 7.26 & 0.06 & 7.33 & 0.06 & 7.34 & 0.06 & 6.94 & 0.06 & 6.95 & 0.06 & 6.92 & 0.05 \\
\hline $28-30$ & 7.13 & 0.04 & 7.12 & 0.04 & 7.11 & 0.04 & 7.26 & 0.06 & 7.27 & 0.06 & 7.27 & 0.05 & 7.02 & 0.06 & 6.99 & 0.06 & 6.98 & 0.05 \\
\hline 29-31 & 7.13 & 0.05 & 7.08 & 0.04 & 7.11 & 0.04 & 7.30 & 0.07 & 7.21 & 0.06 & 7.24 & 0.05 & 6.99 & 0.07 & 6.97 & 0.06 & 7.00 & 0.05 \\
\hline $30-32$ & 7.10 & 0.05 & 7.05 & 0.05 & 7.08 & 0.05 & 7.19 & 0.07 & 7.09 & 0.07 & 7.13 & 0.07 & 7.03 & 0.07 & 7.01 & 0.07 & 7.05 & 0.07 \\
\hline $31-33$ & 7.17 & 0.05 & 7.11 & 0.05 & 7.16 & 0.06 & 7.24 & 0.07 & 7.17 & 0.07 & 7.18 & 0.08 & 7.13 & 0.07 & 7.07 & 0.07 & 7.15 & 0.08 \\
\hline $32-34$ & 7.27 & 0.05 & 7.16 & 0.05 & 7.26 & 0.07 & 7.30 & 0.08 & 7.16 & 0.07 & 7.25 & 0.09 & 7.23 & 0.08 & 7.15 & 0.07 & 7.26 & 0.09 \\
\hline \multicolumn{19}{|c|}{ Cohort 1971-73 } \\
\hline $35-37$ & 7.18 & 0.03 & 7.17 & 0.04 & 7.25 & 0.06 & 7.21 & 0.05 & 7.21 & 0.06 & 7.32 & 0.08 & 7.15 & 0.05 & 7.12 & 0.06 & 7.19 & 0.08 \\
\hline $36-38$ & 7.08 & 0.04 & 7.21 & 0.04 & 7.18 & 0.07 & 7.04 & 0.05 & 7.15 & 0.06 & 7.17 & 0.09 & 7.11 & 0.05 & 7.25 & 0.06 & 7.17 & 0.10 \\
\hline 37-39 & 7.09 & 0.04 & 7.14 & 0.04 & 7.13 & 0.04 & 7.11 & 0.06 & 7.18 & 0.06 & 7.22 & 0.05 & 7.07 & 0.06 & 7.12 & 0.06 & 7.06 & 0.06 \\
\hline $38-40$ & 7.12 & 0.04 & 7.13 & 0.04 & 7.10 & 0.03 & 7.16 & 0.06 & 7.21 & 0.06 & 7.17 & 0.05 & 7.10 & 0.06 & 7.07 & 0.06 & 7.05 & 0.05 \\
\hline 39-41 & 7.18 & 0.04 & 7.16 & 0.04 & 7.13 & 0.04 & 7.29 & 0.06 & 7.31 & 0.05 & 7.24 & 0.05 & 7.09 & 0.06 & 7.04 & 0.06 & 7.05 & 0.06 \\
\hline $40-42$ & 7.21 & 0.05 & 7.11 & 0.04 & 7.11 & 0.05 & 7.30 & 0.07 & 7.25 & 0.06 & 7.20 & 0.06 & 7.14 & 0.06 & 6.99 & 0.06 & 7.04 & 0.08 \\
\hline $41-43$ & 7.21 & 0.05 & 7.10 & 0.04 & 7.10 & 0.06 & 7.28 & 0.07 & 7.20 & 0.06 & 7.17 & 0.09 & 7.16 & 0.07 & 7.03 & 0.06 & 7.05 & 0.10 \\
\hline $42-44$ & 7.22 & 0.05 & 7.06 & 0.05 & 7.08 & 0.08 & 7.30 & 0.07 & 7.18 & 0.06 & 7.17 & 0.11 & 7.15 & 0.07 & 6.97 & 0.06 & 7.02 & 0.12 \\
\hline
\end{tabular}

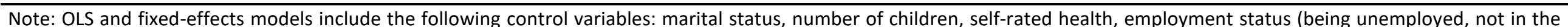
labour force), the natural logarithm of equivalized net household income, whether another person was present during the interview, GDP per capita, and unemployment rate. 


\begin{tabular}{|c|c|c|c|c|c|c|c|c|c|c|c|c|c|c|c|c|c|c|}
\hline \multirow[b]{4}{*}{ Cohort 1991-93 } & \multicolumn{6}{|c|}{ Full sample } & \multicolumn{6}{|c|}{ Men } & \multicolumn{6}{|c|}{ Women } \\
\hline & \multicolumn{2}{|c|}{ Mean } & \multicolumn{2}{|c|}{ OLS } & \multicolumn{2}{|l|}{$\mathrm{FE}$} & \multicolumn{2}{|c|}{ Mean } & \multicolumn{2}{|c|}{ OLS } & \multicolumn{2}{|l|}{$\mathrm{FE}$} & \multicolumn{2}{|c|}{ Mean } & \multicolumn{2}{|c|}{ OLS } & \multicolumn{2}{|l|}{$\mathrm{FE}$} \\
\hline & Margin & SE & Margin & SE & Margin & SE & Margin & SE & Margin & SE & Margin & SE & Margin & SE & Margin & SE & Margin & SE \\
\hline & & & & & & & & & & & & & & & & & & \\
\hline $15-17$ & 8.23 & 0.03 & 8.13 & 0.04 & 8.12 & 0.05 & 8.45 & 0.04 & 8.36 & 0.06 & 8.40 & 0.07 & 8.01 & 0.04 & 7.89 & 0.06 & 7.83 & 0.08 \\
\hline $16-18$ & 7.93 & 0.03 & 7.88 & 0.04 & 7.88 & 0.05 & 8.19 & 0.04 & 8.13 & 0.06 & 8.19 & 0.07 & 7.65 & 0.05 & 7.60 & 0.06 & 7.56 & 0.08 \\
\hline 17-19 & 7.68 & 0.03 & 7.62 & 0.04 & 7.61 & 0.04 & 7.99 & 0.04 & 7.93 & 0.05 & 7.93 & 0.05 & 7.35 & 0.05 & 7.28 & 0.06 & 7.29 & 0.06 \\
\hline $18-20$ & 7.57 & 0.04 & 7.57 & 0.04 & 7.57 & 0.04 & 7.80 & 0.05 & 7.79 & 0.05 & 7.78 & 0.05 & 7.33 & 0.06 & 7.33 & 0.07 & 7.36 & 0.06 \\
\hline 19-21 & 7.33 & 0.04 & 7.30 & 0.05 & 7.31 & 0.04 & 7.65 & 0.05 & 7.64 & 0.06 & 7.62 & 0.06 & 6.99 & 0.06 & 6.95 & 0.07 & 6.98 & 0.06 \\
\hline $20-22$ & 7.26 & 0.04 & 7.26 & 0.05 & 7.28 & 0.05 & 7.52 & 0.05 & 7.55 & 0.06 & 7.51 & 0.06 & 6.99 & 0.06 & 6.97 & 0.08 & 7.04 & 0.07 \\
\hline $21-23$ & 7.16 & 0.04 & 7.20 & 0.05 & 7.20 & 0.05 & 7.47 & 0.06 & 7.51 & 0.06 & 7.47 & 0.07 & 6.85 & 0.07 & 6.90 & 0.08 & 6.91 & 0.08 \\
\hline $22-24$ & 7.06 & 0.05 & 7.08 & 0.05 & 7.06 & 0.07 & 7.28 & 0.06 & 7.26 & 0.07 & 7.22 & 0.09 & 6.84 & 0.07 & 6.89 & 0.08 & 6.87 & 0.09 \\
\hline \multicolumn{19}{|c|}{ Cohort 1981-83 } \\
\hline $25-27$ & 7.14 & 0.03 & 6.97 & 0.04 & 6.98 & 0.05 & 7.38 & 0.05 & 7.30 & 0.07 & 7.25 & 0.08 & 6.90 & 0.05 & 6.69 & 0.06 & 6.71 & 0.07 \\
\hline $26-28$ & 6.97 & 0.04 & 6.88 & 0.05 & 6.84 & 0.05 & 7.24 & 0.05 & 7.14 & 0.07 & 7.08 & 0.09 & 6.71 & 0.05 & 6.65 & 0.06 & 6.61 & 0.07 \\
\hline $27-29$ & 6.75 & 0.04 & 6.71 & 0.04 & 6.70 & 0.04 & 6.97 & 0.06 & 6.91 & 0.06 & 6.91 & 0.05 & 6.55 & 0.06 & 6.54 & 0.06 & 6.51 & 0.05 \\
\hline $28-30$ & 6.81 & 0.04 & 6.79 & 0.04 & 6.80 & 0.03 & 6.95 & 0.06 & 6.96 & 0.06 & 6.97 & 0.05 & 6.68 & 0.06 & 6.66 & 0.06 & 6.65 & 0.05 \\
\hline 29-31 & 6.70 & 0.04 & 6.71 & 0.04 & 6.70 & 0.04 & 6.91 & 0.06 & 6.91 & 0.06 & 6.90 & 0.06 & 6.52 & 0.06 & 6.54 & 0.06 & 6.54 & 0.05 \\
\hline $30-32$ & 6.70 & 0.05 & 6.73 & 0.05 & 6.74 & 0.05 & 6.81 & 0.07 & 6.83 & 0.07 & 6.87 & 0.07 & 6.60 & 0.07 & 6.65 & 0.06 & 6.65 & 0.06 \\
\hline $31-33$ & 6.56 & 0.05 & 6.60 & 0.05 & 6.63 & 0.05 & 6.72 & 0.07 & 6.76 & 0.07 & 6.81 & 0.08 & 6.43 & 0.07 & 6.45 & 0.07 & 6.51 & 0.07 \\
\hline $32-34$ & 6.66 & 0.05 & 6.72 & 0.05 & 6.76 & 0.06 & 6.77 & 0.07 & 6.83 & 0.08 & 6.90 & 0.10 & 6.56 & 0.07 & 6.60 & 0.07 & 6.66 & 0.08 \\
\hline \multicolumn{19}{|c|}{ Cohort 1971-73 } \\
\hline $35-37$ & 6.78 & 0.04 & 6.73 & 0.04 & 6.68 & 0.06 & 6.88 & 0.05 & 6.84 & 0.06 & 6.87 & 0.09 & 6.70 & 0.05 & 6.66 & 0.06 & 6.50 & 0.08 \\
\hline $36-38$ & 6.69 & 0.04 & 6.70 & 0.05 & 6.61 & 0.07 & 6.76 & 0.05 & 6.73 & 0.07 & 6.79 & 0.09 & 6.64 & 0.05 & 6.68 & 0.06 & 6.42 & 0.09 \\
\hline $37-39$ & 6.54 & 0.04 & 6.54 & 0.04 & 6.51 & 0.04 & 6.66 & 0.06 & 6.63 & 0.06 & 6.67 & 0.06 & 6.44 & 0.06 & 6.47 & 0.06 & 6.35 & 0.06 \\
\hline $38-40$ & 6.64 & 0.04 & 6.64 & 0.04 & 6.66 & 0.03 & 6.70 & 0.06 & 6.72 & 0.06 & 6.73 & 0.05 & 6.59 & 0.06 & 6.57 & 0.06 & 6.60 & 0.05 \\
\hline 39-41 & 6.60 & 0.04 & 6.60 & 0.04 & 6.63 & 0.04 & 6.69 & 0.06 & 6.72 & 0.06 & 6.69 & 0.06 & 6.53 & 0.06 & 6.50 & 0.06 & 6.61 & 0.05 \\
\hline $40-42$ & 6.70 & 0.05 & 6.66 & 0.04 & 6.72 & 0.05 & 6.72 & 0.07 & 6.74 & 0.06 & 6.72 & 0.07 & 6.68 & 0.06 & 6.58 & 0.06 & 6.75 & 0.07 \\
\hline $41-43$ & 6.58 & 0.05 & 6.56 & 0.05 & 6.62 & 0.06 & 6.64 & 0.07 & 6.67 & 0.07 & 6.59 & 0.09 & 6.53 & 0.07 & 6.46 & 0.06 & 6.69 & 0.08 \\
\hline $42-44$ & 6.65 & 0.05 & 6.60 & 0.05 & 6.67 & 0.08 & 6.66 & 0.07 & 6.68 & 0.07 & 6.58 & 0.12 & 6.64 & 0.07 & 6.52 & 0.07 & 6.79 & 0.11 \\
\hline
\end{tabular}

Note: OLS and fixed-effects models include the following control variables: marital status, number of children, self-rated health, employment status (being unemployed, not in
labour force), the natural logarithm of equivalized net household income, whether another person was present during the interview, GDP per capita, and unemployment rate. 


\begin{tabular}{|c|c|c|c|c|c|c|c|c|c|c|c|c|c|c|c|c|c|c|}
\hline \multirow{4}{*}{ Cohort 1991-93 } & \multicolumn{6}{|c|}{ Full sample } & \multicolumn{6}{|c|}{ Men } & \multicolumn{6}{|c|}{ Women } \\
\hline & \multicolumn{2}{|c|}{ Mean } & \multicolumn{2}{|c|}{ OLS } & \multicolumn{2}{|l|}{$\mathrm{FE}$} & \multicolumn{2}{|c|}{ Mean } & \multicolumn{2}{|c|}{ OLS } & \multicolumn{2}{|l|}{$\mathrm{FE}$} & \multicolumn{2}{|c|}{ Mean } & \multicolumn{2}{|c|}{ OLS } & \multicolumn{2}{|c|}{$\mathrm{FE}$} \\
\hline & Margin & SE & Margin & SE & Margin & SE & Margin & SE & Margin & SE & Margin & SE & Margin & SE & Margin & SE & Margin & SE \\
\hline & & & & & & & & & & & & & & & & & & \\
\hline $15-17$ & 8.79 & 0.02 & 8.72 & 0.04 & 8.71 & 0.05 & 8.77 & 0.03 & 8.72 & 0.05 & 8.71 & 0.06 & 8.81 & 0.04 & 8.73 & 0.05 & 8.72 & 0.07 \\
\hline $16-18$ & 8.61 & 0.03 & 8.54 & 0.04 & 8.53 & 0.05 & 8.63 & 0.04 & 8.57 & 0.05 & 8.54 & 0.07 & 8.59 & 0.04 & 8.52 & 0.05 & 8.51 & 0.07 \\
\hline 17-19 & 8.46 & 0.03 & 8.44 & 0.04 & 8.42 & 0.04 & 8.54 & 0.04 & 8.53 & 0.05 & 8.51 & 0.05 & 8.39 & 0.04 & 8.34 & 0.06 & 8.31 & 0.05 \\
\hline $18-20$ & 8.25 & 0.03 & 8.22 & 0.04 & 8.24 & 0.03 & 8.35 & 0.04 & 8.32 & 0.05 & 8.31 & 0.04 & 8.14 & 0.05 & 8.11 & 0.06 & 8.16 & 0.05 \\
\hline 19-21 & 8.11 & 0.03 & 8.10 & 0.04 & 8.10 & 0.04 & 8.20 & 0.05 & 8.20 & 0.05 & 8.19 & 0.05 & 8.02 & 0.05 & 8.00 & 0.06 & 8.01 & 0.05 \\
\hline $20-22$ & 7.95 & 0.04 & 7.96 & 0.04 & 7.98 & 0.04 & 7.98 & 0.05 & 7.99 & 0.06 & 8.03 & 0.06 & 7.91 & 0.05 & 7.91 & 0.06 & 7.93 & 0.06 \\
\hline $21-23$ & 7.87 & 0.04 & 7.90 & 0.05 & 7.90 & 0.05 & 8.01 & 0.05 & 8.02 & 0.06 & 8.03 & 0.07 & 7.74 & 0.06 & 7.77 & 0.07 & 7.76 & 0.07 \\
\hline $22-24$ & 7.72 & 0.04 & 7.74 & 0.05 & 7.74 & 0.06 & 7.75 & 0.05 & 7.74 & 0.07 & 7.78 & 0.09 & 7.69 & 0.06 & 7.73 & 0.07 & 7.71 & 0.09 \\
\hline \multicolumn{19}{|c|}{ Cohort 1981-83 } \\
\hline $25-27$ & 8.02 & 0.03 & 7.93 & 0.04 & 7.85 & 0.05 & 7.99 & 0.04 & 7.93 & 0.06 & 7.79 & 0.07 & 8.05 & 0.04 & 7.93 & 0.06 & 7.90 & 0.06 \\
\hline $26-28$ & 7.78 & 0.03 & 7.74 & 0.04 & 7.68 & 0.05 & 7.78 & 0.05 & 7.73 & 0.06 & 7.64 & 0.08 & 7.78 & 0.05 & 7.75 & 0.06 & 7.72 & 0.07 \\
\hline $27-29$ & 7.56 & 0.04 & 7.56 & 0.04 & 7.53 & 0.03 & 7.49 & 0.05 & 7.46 & 0.06 & 7.43 & 0.05 & 7.64 & 0.05 & 7.65 & 0.06 & 7.62 & 0.05 \\
\hline $28-30$ & 7.44 & 0.04 & 7.46 & 0.04 & 7.45 & 0.03 & 7.30 & 0.06 & 7.31 & 0.06 & 7.34 & 0.04 & 7.56 & 0.05 & 7.58 & 0.06 & 7.56 & 0.04 \\
\hline 29-31 & 7.41 & 0.04 & 7.43 & 0.04 & 7.44 & 0.03 & 7.30 & 0.06 & 7.29 & 0.06 & 7.33 & 0.05 & 7.50 & 0.06 & 7.55 & 0.06 & 7.53 & 0.05 \\
\hline 30-32 & 7.31 & 0.04 & 7.33 & 0.04 & 7.37 & 0.04 & 7.22 & 0.06 & 7.23 & 0.06 & 7.29 & 0.07 & 7.39 & 0.06 & 7.43 & 0.06 & 7.44 & 0.05 \\
\hline 31-33 & 7.19 & 0.05 & 7.20 & 0.05 & 7.30 & 0.05 & 7.09 & 0.06 & 7.12 & 0.07 & 7.23 & 0.08 & 7.28 & 0.06 & 7.28 & 0.07 & 7.37 & 0.07 \\
\hline $32-34$ & 7.17 & 0.05 & 7.18 & 0.05 & 7.30 & 0.06 & 6.96 & 0.07 & 6.99 & 0.08 & 7.14 & 0.10 & 7.35 & 0.07 & 7.36 & 0.07 & 7.45 & 0.08 \\
\hline \multicolumn{19}{|c|}{ Cohort 1971-73 } \\
\hline $35-37$ & 7.67 & 0.03 & 7.63 & 0.04 & 7.65 & 0.05 & 7.42 & 0.05 & 7.37 & 0.06 & 7.43 & 0.08 & 7.89 & 0.04 & 7.85 & 0.05 & 7.81 & 0.07 \\
\hline $36-38$ & 7.50 & 0.03 & 7.48 & 0.04 & 7.51 & 0.07 & 7.28 & 0.05 & 7.23 & 0.06 & 7.37 & 0.09 & 7.67 & 0.05 & 7.68 & 0.06 & 7.63 & 0.09 \\
\hline 37-39 & 7.26 & 0.04 & 7.25 & 0.04 & 7.27 & 0.04 & 7.11 & 0.06 & 7.09 & 0.06 & 7.15 & 0.05 & 7.38 & 0.05 & 7.39 & 0.06 & 7.37 & 0.06 \\
\hline $38-40$ & 7.25 & 0.04 & 7.25 & 0.04 & 7.25 & 0.03 & 7.00 & 0.06 & 7.02 & 0.06 & 7.01 & 0.04 & 7.45 & 0.05 & 7.44 & 0.05 & 7.45 & 0.04 \\
\hline 39-41 & 7.19 & 0.04 & 7.20 & 0.04 & 7.20 & 0.04 & 7.02 & 0.06 & 7.06 & 0.06 & 6.98 & 0.05 & 7.33 & 0.05 & 7.33 & 0.05 & 7.37 & 0.05 \\
\hline 40-42 & 7.26 & 0.04 & 7.24 & 0.04 & 7.23 & 0.05 & 7.12 & 0.06 & 7.14 & 0.06 & 7.08 & 0.07 & 7.36 & 0.06 & 7.31 & 0.06 & 7.37 & 0.07 \\
\hline 41-43 & 7.10 & 0.04 & 7.10 & 0.05 & 7.07 & 0.06 & 6.89 & 0.07 & 6.92 & 0.07 & 6.83 & 0.09 & 7.26 & 0.06 & 7.23 & 0.06 & 7.28 & 0.09 \\
\hline $42-44$ & 7.18 & 0.05 & 7.17 & 0.05 & 7.10 & 0.08 & 7.02 & 0.07 & 7.06 & 0.07 & 6.89 & 0.11 & 7.31 & 0.06 & 7.26 & 0.06 & 7.28 & 0.11 \\
\hline
\end{tabular}

Note: OLS and fixed-effects models include the following control variables: marital status, number of children, self-rated health, employment status (being unemployed, not in the labour force), the natural logarithm of equivalized net household income, whether another person was present during the interview, GDP per capita, and unemployment rate. 


\begin{tabular}{|c|c|c|c|c|c|c|c|c|c|c|c|c|c|c|c|c|c|c|}
\hline \multirow{4}{*}{ Cohort 1991-93 } & \multicolumn{6}{|c|}{ Full sample } & \multicolumn{6}{|c|}{ Men } & \multicolumn{6}{|c|}{ Women } \\
\hline & \multicolumn{2}{|c|}{ Mean } & \multicolumn{2}{|c|}{ OLS } & \multicolumn{2}{|l|}{$\mathrm{FE}$} & \multicolumn{2}{|c|}{ Mean } & \multicolumn{2}{|c|}{ OLS } & \multicolumn{2}{|l|}{$\mathrm{FE}$} & \multicolumn{2}{|c|}{ Mean } & \multicolumn{2}{|c|}{ OLS } & \multicolumn{2}{|l|}{ FE } \\
\hline & Margin & SE & Margin & SE & Margin & SE & Margin & SE & Margin & SE & Margin & SE & Margin & SE & Margin & SE & Margin & SE \\
\hline & & & & & & & & & & & & & & & & & & \\
\hline $15-17$ & 8.75 & 0.03 & 8.71 & 0.04 & 8.65 & 0.04 & 8.76 & 0.03 & 8.69 & 0.05 & 8.62 & 0.06 & 8.74 & 0.04 & 8.73 & 0.06 & 8.68 & 0.06 \\
\hline $16-18$ & 8.61 & 0.03 & 8.59 & 0.04 & 8.53 & 0.04 & 8.60 & 0.04 & 8.57 & 0.05 & 8.52 & 0.06 & 8.61 & 0.04 & 8.62 & 0.06 & 8.55 & 0.06 \\
\hline $17-19$ & 8.47 & 0.03 & 8.45 & 0.04 & 8.41 & 0.03 & 8.49 & 0.04 & 8.46 & 0.05 & 8.41 & 0.04 & 8.45 & 0.04 & 8.44 & 0.06 & 8.42 & 0.05 \\
\hline $18-20$ & 8.45 & 0.03 & 8.40 & 0.04 & 8.41 & 0.03 & 8.47 & 0.04 & 8.46 & 0.05 & 8.47 & 0.04 & 8.43 & 0.05 & 8.33 & 0.06 & 8.35 & 0.04 \\
\hline 19-21 & 8.34 & 0.03 & 8.32 & 0.04 & 8.36 & 0.03 & 8.32 & 0.05 & 8.31 & 0.05 & 8.36 & 0.05 & 8.36 & 0.05 & 8.32 & 0.06 & 8.37 & 0.05 \\
\hline $20-22$ & 8.36 & 0.04 & 8.36 & 0.04 & 8.42 & 0.04 & 8.31 & 0.05 & 8.33 & 0.06 & 8.41 & 0.06 & 8.40 & 0.05 & 8.38 & 0.06 & 8.43 & 0.06 \\
\hline $21-23$ & 8.32 & 0.04 & 8.30 & 0.05 & 8.35 & 0.04 & 8.28 & 0.05 & 8.29 & 0.06 & 8.36 & 0.06 & 8.36 & 0.06 & 8.31 & 0.07 & 8.34 & 0.06 \\
\hline $22-24$ & 8.28 & 0.04 & 8.27 & 0.05 & 8.33 & 0.05 & 8.18 & 0.06 & 8.20 & 0.06 & 8.27 & 0.08 & 8.38 & 0.06 & 8.34 & 0.06 & 8.39 & 0.07 \\
\hline \multicolumn{19}{|c|}{ Cohort 1981-83 } \\
\hline $25-27$ & 8.53 & 0.03 & 8.73 & 0.04 & 8.66 & 0.05 & 8.38 & 0.04 & 8.63 & 0.05 & 8.51 & 0.07 & 8.69 & 0.04 & 8.81 & 0.05 & 8.78 & 0.06 \\
\hline $26-28$ & 8.47 & 0.03 & 8.57 & 0.04 & 8.52 & 0.05 & 8.38 & 0.05 & 8.52 & 0.05 & 8.40 & 0.07 & 8.55 & 0.04 & 8.60 & 0.05 & 8.62 & 0.07 \\
\hline $27-29$ & 8.33 & 0.03 & 8.38 & 0.04 & 8.39 & 0.03 & 8.22 & 0.05 & 8.26 & 0.05 & 8.26 & 0.05 & 8.44 & 0.05 & 8.49 & 0.05 & 8.51 & 0.04 \\
\hline $28-30$ & 8.32 & 0.04 & 8.33 & 0.04 & 8.35 & 0.03 & 8.18 & 0.05 & 8.19 & 0.05 & 8.24 & 0.04 & 8.45 & 0.05 & 8.45 & 0.05 & 8.46 & 0.04 \\
\hline $29-31$ & 8.25 & 0.04 & 8.26 & 0.04 & 8.28 & 0.03 & 8.10 & 0.06 & 8.09 & 0.06 & 8.14 & 0.05 & 8.38 & 0.05 & 8.40 & 0.05 & 8.40 & 0.04 \\
\hline 30-32 & 8.23 & 0.04 & 8.17 & 0.04 & 8.19 & 0.04 & 8.06 & 0.06 & 7.98 & 0.06 & 8.03 & 0.06 & 8.39 & 0.05 & 8.34 & 0.05 & 8.33 & 0.05 \\
\hline $31-33$ & 8.15 & 0.04 & 8.07 & 0.04 & 8.10 & 0.05 & 7.99 & 0.06 & 7.89 & 0.06 & 7.95 & 0.07 & 8.30 & 0.06 & 8.24 & 0.06 & 8.25 & 0.07 \\
\hline $32-34$ & 8.19 & 0.04 & 8.09 & 0.05 & 8.15 & 0.06 & 7.94 & 0.07 & 7.82 & 0.07 & 7.95 & 0.09 & 8.40 & 0.06 & 8.34 & 0.06 & 8.33 & 0.09 \\
\hline \multicolumn{19}{|c|}{ Cohort 1971-73 } \\
\hline $35-37$ & 8.54 & 0.03 & 8.63 & 0.03 & 8.59 & 0.04 & 8.47 & 0.04 & 8.65 & 0.05 & 8.65 & 0.06 & 8.60 & 0.04 & 8.59 & 0.05 & 8.53 & 0.06 \\
\hline $36-38$ & 8.42 & 0.03 & 8.37 & 0.04 & 8.34 & 0.05 & 8.37 & 0.05 & 8.34 & 0.05 & 8.39 & 0.07 & 8.46 & 0.04 & 8.40 & 0.05 & 8.30 & 0.08 \\
\hline $37-39$ & 8.30 & 0.03 & 8.27 & 0.04 & 8.28 & 0.03 & 8.23 & 0.05 & 8.20 & 0.05 & 8.23 & 0.05 & 8.37 & 0.05 & 8.34 & 0.05 & 8.32 & 0.05 \\
\hline $38-40$ & 8.27 & 0.04 & 8.29 & 0.04 & 8.31 & 0.03 & 8.25 & 0.05 & 8.29 & 0.05 & 8.30 & 0.04 & 8.28 & 0.05 & 8.29 & 0.05 & 8.32 & 0.04 \\
\hline 39-41 & 8.18 & 0.04 & 8.22 & 0.04 & 8.24 & 0.03 & 8.21 & 0.06 & 8.26 & 0.05 & 8.23 & 0.04 & 8.16 & 0.05 & 8.20 & 0.05 & 8.25 & 0.05 \\
\hline 40-42 & 8.23 & 0.04 & 8.23 & 0.04 & 8.26 & 0.04 & 8.26 & 0.06 & 8.27 & 0.06 & 8.25 & 0.06 & 8.20 & 0.05 & 8.20 & 0.05 & 8.26 & 0.06 \\
\hline 41-43 & 8.16 & 0.04 & 8.20 & 0.04 & 8.22 & 0.05 & 8.09 & 0.06 & 8.13 & 0.06 & 8.11 & 0.07 & 8.21 & 0.05 & 8.25 & 0.05 & 8.30 & 0.07 \\
\hline $42-44$ & 8.16 & 0.04 & 8.21 & 0.04 & 8.22 & 0.06 & 8.15 & 0.06 & 8.19 & 0.06 & 8.14 & 0.09 & 8.17 & 0.06 & 8.22 & 0.06 & 8.29 & 0.09 \\
\hline
\end{tabular}

Note: OLS and fixed-effects models include the following control variables: marital status, number of children, self-rated health, employment status (being unemployed, not in the labour force), the natural logarithm of equivalized net household income, whether another person was present during the interview, GDP per capita, and unemployment rate. 
Figure A.1: Sequential cohort design of pairfam data, 2008-2015

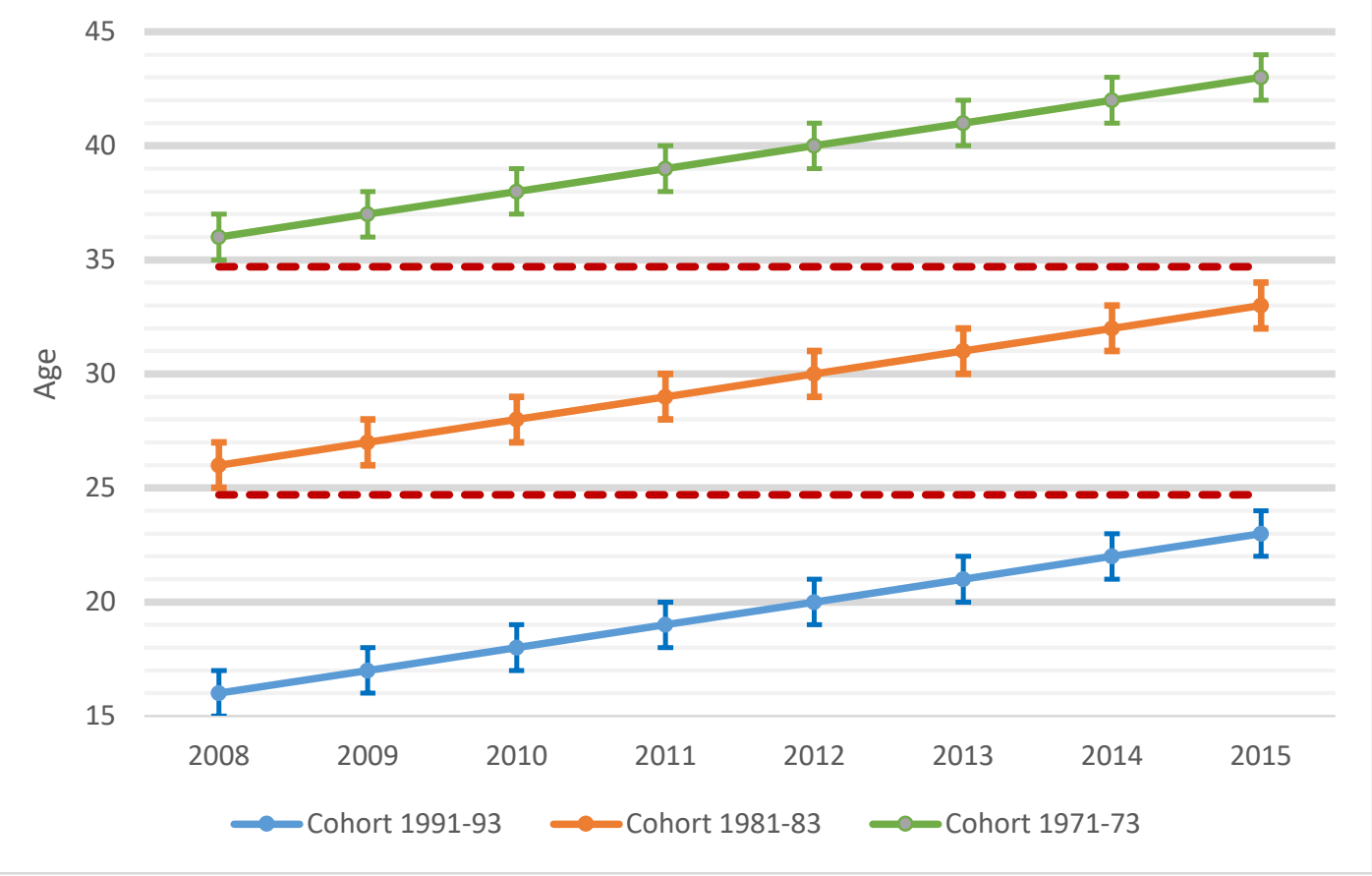




\section{Supplementary material}

Table S.1. Overall life satisfaction, OLS, and FE estimates, full sample

\begin{tabular}{|c|c|c|c|c|c|c|c|c|c|c|c|c|}
\hline & \multicolumn{4}{|c|}{ 1991-93 } & \multicolumn{4}{|c|}{ 1981-83 } & \multicolumn{4}{|c|}{$1971-73$} \\
\hline & \multicolumn{2}{|c|}{ OLS } & \multicolumn{2}{|l|}{ FE } & \multicolumn{2}{|c|}{ OLS } & \multicolumn{2}{|c|}{ FE } & \multicolumn{2}{|c|}{ OLS } & \multicolumn{2}{|c|}{ FE } \\
\hline & Coef & SE & Coef & SE & Coef & SE & Coef & SE & Coef & SE & Coef & SE \\
\hline Unemployed & $-1.073 * * *$ & 0.10 & $-0.775 * * *$ & 0.09 & $-0.887 * * *$ & 0.07 & $-0.459 * * *$ & 0.07 & $-0.886 * * *$ & 0.09 & $-0.547 * * *$ & 0.09 \\
\hline Not in labour force & 0.017 & 0.03 & -0.033 & 0.04 & $0.071 *$ & 0.04 & $0.141 * * *$ & 0.04 & -0.054 & 0.06 & 0.008 & 0.06 \\
\hline Married & $0.404^{* *}$ & 0.18 & $0.331 *$ & 0.17 & $0.480 * * *$ & 0.04 & 0.064 & 0.05 & $0.483 * * *$ & 0.04 & $0.183^{* *}$ & 0.07 \\
\hline Number of children & -0.087 & 0.11 & 0.061 & 0.12 & $0.042 *$ & 0.02 & 0.015 & 0.04 & $0.064 * * *$ & 0.02 & 0.012 & 0.04 \\
\hline Good health & $0.652 * * *$ & 0.03 & $0.327 * * *$ & 0.03 & $0.686 * * *$ & 0.03 & $0.333 * * *$ & 0.03 & $0.674 * * *$ & 0.03 & $0.267 * * *$ & 0.03 \\
\hline Bad health & $-0.455^{* * *}$ & 0.06 & $-0.407 * * *$ & 0.05 & $-0.504 * * *$ & 0.06 & $-0.434 * * *$ & 0.05 & $-0.719 * * *$ & 0.06 & $-0.459 * * *$ & 0.05 \\
\hline Ln equivalised h'hold income & $0.204^{* * *}$ & 0.03 & $0.080 * * *$ & 0.03 & $0.456 * * *$ & 0.04 & $0.186 * * *$ & 0.04 & $0.559 * * *$ & 0.04 & $0.327 * * *$ & 0.05 \\
\hline Others present during interview & -0.019 & 0.05 & 0.072 & 0.05 & $0.105^{* * *}$ & 0.04 & $0.084 * *$ & 0.04 & $0.108 * * *$ & 0.04 & $0.132 * * *$ & 0.03 \\
\hline Unemployment rate & $-0.020 * *$ & 0.01 & $0.051^{* * *}$ & 0.02 & $-0.015^{*}$ & 0.01 & -0.008 & 0.02 & -0.008 & 0.01 & -0.018 & 0.02 \\
\hline BIP per capita & -0.000 & 0.00 & -0.000 & 0.00 & $-0.000 * *$ & 0.00 & -0.000 & 0.00 & 0.000 & 0.00 & 0.000 & 0.00 \\
\hline Year 2009 & $0.138 * * *$ & 0.04 & $0.138 * * *$ & 0.04 & $0.091 * *$ & 0.04 & $0.082 * *$ & 0.04 & $0.088^{* *}$ & 0.04 & $0.088 * *$ & 0.04 \\
\hline Year 2010 & -0.059 & 0.04 & -0.027 & 0.04 & 0.006 & 0.04 & 0.028 & 0.04 & -0.058 & 0.04 & -0.028 & 0.04 \\
\hline Year 2011 & $-0.169 * * *$ & 0.05 & -0.057 & 0.06 & -0.040 & 0.05 & 0.006 & 0.06 & $-0.140 * * *$ & 0.04 & $-0.137^{* *}$ & 0.06 \\
\hline Year 2012 & $-0.145^{* * *}$ & 0.05 & -0.003 & 0.06 & -0.049 & 0.05 & 0.016 & 0.06 & -0.042 & 0.04 & -0.060 & 0.06 \\
\hline Year 2013 & $-0.201 * * *$ & 0.05 & -0.047 & 0.07 & -0.004 & 0.05 & 0.078 & 0.07 & $-0.133 * * *$ & 0.05 & -0.118 & 0.07 \\
\hline Year 2014 & $-0.228 * * *$ & 0.05 & -0.077 & 0.07 & -0.085 & 0.05 & 0.026 & 0.07 & $-0.123 * * *$ & 0.05 & -0.120 & 0.08 \\
\hline Year 2015 & $-0.319 * * *$ & 0.06 & $-0.141 *$ & 0.08 & $-0.173 * * *$ & 0.05 & -0.027 & 0.08 & $-0.129 * * *$ & 0.05 & -0.130 & 0.09 \\
\hline Constant & $6.254 * * *$ & 0.26 & $6.803 * * *$ & 0.37 & $4.031 * * *$ & 0.31 & $6.218^{* * *}$ & 0.38 & $2.729 * * *$ & 0.36 & $4.960 * * *$ & 0.46 \\
\hline Number of observations & & 14,670 & & 14,670 & & 17,869 & & 17,869 & & 19,888 & & 19,888 \\
\hline Number of groups & & & & 3,607 & & & & 4,174 & & & & 4,384 \\
\hline $\mathrm{R}^{2}$ overall & & & & 0.080 & & & & 0.144 & & & & 0.188 \\
\hline $\mathrm{R}^{2}$ within & & & & 0.059 & & & & 0.044 & & & & 0.042 \\
\hline$R^{2}$ between & & & & 0.083 & & & & 0.169 & & & & 0.253 \\
\hline
\end{tabular}

Note: ${ }^{* * *} \mathrm{p}<0.01, * * \mathrm{p}<0.05, * \mathrm{p}<0.1$ 
Table S.2. Satisfaction with school, education, career, OLS, and FE estimates, full sample

\begin{tabular}{|c|c|c|c|c|c|c|c|c|c|c|c|c|}
\hline & \multicolumn{4}{|c|}{ 1991-93 } & \multicolumn{4}{|c|}{$1981-83$} & \multicolumn{4}{|c|}{$1971-73$} \\
\hline & \multicolumn{2}{|c|}{ OLS } & \multicolumn{2}{|l|}{ FE } & \multicolumn{2}{|c|}{ OLS } & \multicolumn{2}{|l|}{ FE } & \multicolumn{2}{|c|}{ OLS } & \multicolumn{2}{|c|}{ FE } \\
\hline & Coef & SE & Coef & SE & Coef & SE & Coef & SE & Coef & SE & Coef & SE \\
\hline Unemployed & $-3.433 * * *$ & 0.15 & $-2.912 * * *$ & 0.16 & $-2.322 * * *$ & 0.11 & $-1.800 * * *$ & 0.12 & $-2.403 * * *$ & 0.11 & $-1.566 * * *$ & 0.13 \\
\hline Not in labour force & $-0.250 * * *$ & 0.04 & $-0.315^{* * *}$ & 0.05 & $-0.315^{* * *}$ & 0.06 & $-0.158 * * *$ & 0.06 & $-0.644 * * *$ & 0.08 & $-0.410 * * *$ & 0.08 \\
\hline Married & -0.364 & 0.26 & -0.317 & 0.24 & $0.172 * * *$ & 0.05 & -0.057 & 0.06 & 0.042 & 0.05 & $-0.163^{*}$ & 0.08 \\
\hline Number of children & $-0.780 * * *$ & 0.15 & $-0.328 *$ & 0.17 & $-0.124 * * *$ & 0.03 & -0.048 & 0.05 & $0.058 * * *$ & 0.02 & 0.015 & 0.06 \\
\hline Good health & $0.571 * * *$ & 0.04 & $0.278 * * *$ & 0.05 & $0.623 * * *$ & 0.04 & $0.213^{* * *}$ & 0.04 & $0.507^{* * *}$ & 0.04 & $0.165^{* * *}$ & 0.04 \\
\hline Bad health & $-0.204 * * *$ & 0.07 & -0.112 & 0.07 & $-0.254 * * *$ & 0.07 & $-0.168 * * *$ & 0.07 & $-0.446 * * *$ & 0.06 & $-0.261 * * *$ & 0.06 \\
\hline Ln equivalised h'hold income & $0.117^{* * *}$ & 0.03 & -0.027 & 0.04 & $0.475^{* * *}$ & 0.04 & 0.074 & 0.05 & $0.677^{* * *}$ & 0.05 & $0.277 * * *$ & 0.06 \\
\hline Others present during interview & $-0.203 * * *$ & 0.07 & 0.002 & 0.07 & $-0.099 *$ & 0.05 & -0.021 & 0.05 & -0.058 & 0.05 & -0.011 & 0.04 \\
\hline Unemployment rate & $-0.047 * * *$ & 0.01 & 0.007 & 0.03 & -0.016 & 0.01 & 0.007 & 0.02 & -0.016 & 0.01 & -0.025 & 0.03 \\
\hline BIP per capita & $-0.000 * *$ & 0.00 & -0.000 & 0.00 & $-0.000 * * *$ & 0.00 & -0.000 & 0.00 & -0.000 & 0.00 & -0.000 & 0.00 \\
\hline Year 2009 & 0.015 & 0.05 & 0.010 & 0.05 & -0.027 & 0.05 & -0.055 & 0.06 & 0.044 & 0.05 & -0.079 & 0.05 \\
\hline Year 2010 & 0.020 & 0.06 & $0.107 *$ & 0.06 & -0.002 & 0.06 & 0.034 & 0.06 & -0.022 & 0.05 & $-0.124 * *$ & 0.05 \\
\hline Year 2011 & $0.110^{*}$ & 0.06 & $0.257 * * *$ & 0.08 & -0.011 & 0.06 & 0.031 & 0.08 & -0.034 & 0.05 & $-0.153 * *$ & 0.08 \\
\hline Year 2012 & $0.143 * *$ & 0.06 & $0.285^{* * *}$ & 0.09 & -0.048 & 0.06 & 0.025 & 0.08 & -0.005 & 0.06 & -0.125 & 0.09 \\
\hline Year 2013 & 0.088 & 0.07 & $0.232 * *$ & 0.09 & -0.080 & 0.07 & 0.000 & 0.09 & -0.061 & 0.06 & -0.145 & 0.10 \\
\hline Year 2014 & $0.184^{* * *}$ & 0.07 & $0.302 * * *$ & 0.10 & -0.017 & 0.07 & 0.077 & 0.10 & -0.062 & 0.06 & -0.156 & 0.11 \\
\hline Year 2015 & 0.111 & 0.07 & $0.242^{* *}$ & 0.11 & 0.032 & 0.07 & 0.172 & 0.11 & $-0.106^{*}$ & 0.06 & -0.172 & 0.13 \\
\hline Constant & $7.069 * * *$ & 0.30 & $7.834 * * *$ & 0.46 & $4.123^{* * *}$ & 0.39 & $6.962 * * *$ & 0.50 & $2.314 * * *$ & 0.41 & $5.877^{* * *}$ & 0.62 \\
\hline Number of observations & & 14,640 & & 14,640 & & 17,763 & & 17,763 & & 19,758 & & 19,758 \\
\hline Number of groups & & & & 3,607 & & & & 4,168 & & & & 4,374 \\
\hline $\mathrm{R}^{2}$ overall & & & & 0.115 & & & & 0.139 & & & & 0.148 \\
\hline $\mathrm{R}^{2}$ within & & & & 0.078 & & & & 0.050 & & & & 0.035 \\
\hline$R^{2}$ between & & & & 0.129 & & & & 0.192 & & & & 0.202 \\
\hline
\end{tabular}

Note: ${ }^{* * *} \mathrm{p}<0.01,{ }^{* *} \mathrm{p}<0.05, * \mathrm{p}<0.1$ 
Table S.3. Satisfaction with leisure activities, hobbies, interests, OLS, and FE estimates, full sample

\begin{tabular}{|c|c|c|c|c|c|c|c|c|c|c|c|c|}
\hline & \multicolumn{4}{|c|}{ 1991-93 } & \multicolumn{4}{|c|}{$1981-83$} & \multicolumn{4}{|c|}{$1971-73$} \\
\hline & \multicolumn{2}{|c|}{ OLS } & \multicolumn{2}{|l|}{ FE } & \multicolumn{2}{|c|}{ OLS } & \multicolumn{2}{|l|}{ FE } & \multicolumn{2}{|c|}{ OLS } & \multicolumn{2}{|l|}{ FE } \\
\hline & Coef & SE & Coef & SE & Coef & SE & Coef & SE & Coef & SE & Coef & SE \\
\hline Unemployed & -0.150 & 0.11 & -0.036 & 0.12 & -0.049 & 0.08 & $0.146 *$ & 0.08 & $-0.372 * * *$ & 0.10 & -0.152 & 0.10 \\
\hline Not in labour force & 0.033 & 0.04 & $0.091 * *$ & 0.05 & -0.051 & 0.06 & 0.072 & 0.05 & $-0.164 * *$ & 0.08 & -0.005 & 0.07 \\
\hline Married & $-0.543 * *$ & 0.26 & -0.281 & 0.25 & -0.007 & 0.06 & $-0.140 * *$ & 0.06 & $0.143^{* *}$ & 0.06 & -0.138 & 0.09 \\
\hline Number of children & $-0.550 * * *$ & 0.12 & $-0.313^{*}$ & 0.16 & $-0.316 * * *$ & 0.03 & $-0.347 * * *$ & 0.05 & $-0.177 * * *$ & 0.03 & $-0.393 * * *$ & 0.06 \\
\hline Good health & $0.517^{* * *}$ & 0.05 & $0.225^{* * *}$ & 0.04 & $0.638 * * *$ & 0.05 & $0.281 * * *$ & 0.04 & $0.725 * * *$ & 0.04 & $0.231 * * *$ & 0.04 \\
\hline Bad health & $-0.287 * * *$ & 0.07 & $-0.177^{* * *}$ & 0.07 & -0.089 & 0.07 & -0.082 & 0.06 & $-0.269 * * *$ & 0.07 & $-0.103 * *$ & 0.05 \\
\hline Ln equivalised h'hold income & $0.182^{* * *}$ & 0.03 & $0.060 *$ & 0.03 & $0.163^{* * *}$ & 0.04 & -0.047 & 0.05 & 0.056 & 0.05 & -0.019 & 0.05 \\
\hline Others present during interview & 0.024 & 0.06 & -0.051 & 0.07 & $-0.108 * *$ & 0.05 & -0.072 & 0.05 & -0.046 & 0.05 & -0.014 & 0.04 \\
\hline Unemployment rate & -0.019 & 0.01 & 0.021 & 0.02 & $-0.021^{*}$ & 0.01 & -0.029 & 0.02 & $-0.032 * *$ & 0.01 & 0.023 & 0.02 \\
\hline BIP per capita & $-0.000 * *$ & 0.00 & $0.000 *$ & 0.00 & $-0.000 * *$ & 0.00 & -0.000 & 0.00 & -0.000 & 0.00 & 0.000 & 0.00 \\
\hline Year 2009 & $-0.253 * * *$ & 0.05 & $-0.242 * * *$ & 0.05 & $-0.095^{*}$ & 0.05 & $-0.134 * *$ & 0.05 & -0.028 & 0.05 & -0.076 & 0.05 \\
\hline Year 2010 & $-0.514 * * *$ & 0.05 & $-0.505^{* * *}$ & 0.06 & $-0.264 * * *$ & 0.05 & $-0.277^{* * *}$ & 0.06 & $-0.186 * * *$ & 0.05 & $-0.177 * * *$ & 0.06 \\
\hline Year 2011 & $-0.566 * * *$ & 0.06 & $-0.549 * * *$ & 0.07 & $-0.181 * * *$ & 0.06 & $-0.180 * *$ & 0.07 & -0.090 & 0.06 & -0.028 & 0.08 \\
\hline Year 2012 & $-0.832 * * *$ & 0.06 & $-0.806 * * *$ & 0.08 & $-0.264 * * *$ & 0.06 & $-0.278 * * *$ & 0.08 & $-0.126 * *$ & 0.06 & -0.050 & 0.09 \\
\hline Year 2013 & $-0.877 * * *$ & 0.06 & $-0.835 * * *$ & 0.09 & $-0.241 * * *$ & 0.06 & $-0.236 * * *$ & 0.09 & -0.069 & 0.06 & 0.035 & 0.10 \\
\hline Year 2014 & $-0.929 * * *$ & 0.07 & $-0.920 * * *$ & 0.09 & $-0.376 * * *$ & 0.07 & $-0.345^{* * *}$ & 0.10 & $-0.171 * * *$ & 0.06 & -0.061 & 0.11 \\
\hline Year 2015 & $-1.056 * * *$ & 0.07 & $-1.058 * * *$ & 0.10 & $-0.254 * * *$ & 0.07 & $-0.218^{* *}$ & 0.11 & $-0.131 * *$ & 0.07 & -0.017 & 0.13 \\
\hline Constant & $6.985^{* * *}$ & 0.31 & $6.880 * * *$ & 0.44 & $6.131 * * *$ & 0.39 & $7.874^{* * *}$ & 0.45 & $6.558 * * *$ & 0.47 & $7.038 * * *$ & 0.60 \\
\hline Number of observations & & 14,671 & & 14,671 & & 17,864 & & 17,864 & & 19,879 & & 19,879 \\
\hline Number of groups & & & & 3,607 & & & & 4,173 & & & & 4,382 \\
\hline $\mathrm{R}^{2}$ overall & & & & 0.060 & & & & 0.046 & & & & 0.018 \\
\hline $\mathrm{R}^{2}$ within & & & & 0.055 & & & & 0.023 & & & & 0.012 \\
\hline$R^{2}$ between & & & & 0.075 & & & & 0.057 & & & & 0.025 \\
\hline
\end{tabular}

Note: ${ }^{* * *} \mathrm{p}<0.01,{ }^{* *} \mathrm{p}<0.05, * \mathrm{p}<0.1$ 
Table S.4. Satisfaction with friends and social contacts, OLS, and FE estimates, full sample

\begin{tabular}{|c|c|c|c|c|c|c|c|c|c|c|c|c|}
\hline & \multicolumn{4}{|c|}{ 1991-93 } & \multicolumn{4}{|c|}{ 1981-83 } & \multicolumn{4}{|c|}{ 1971-73 } \\
\hline & \multicolumn{2}{|c|}{ OLS } & \multicolumn{2}{|l|}{ FE } & \multicolumn{2}{|c|}{ OLS } & \multicolumn{2}{|l|}{$\mathrm{FE}$} & \multicolumn{2}{|c|}{ OLS } & \multicolumn{2}{|l|}{ FE } \\
\hline & Coef & SE & Coef & SE & Coef & SE & Coef & SE & Coef & SE & Coef & SE \\
\hline Unemployed & $-0.197^{*}$ & 0.11 & -0.078 & 0.11 & $-0.137 *$ & 0.08 & $0.130 *$ & 0.07 & $-0.353^{* * *}$ & 0.11 & 0.008 & 0.10 \\
\hline Not in labour force & $0.064^{*}$ & 0.04 & $0.068 *$ & 0.04 & 0.059 & 0.06 & $0.112 * *$ & 0.05 & -0.026 & 0.07 & -0.002 & 0.06 \\
\hline Married & $-0.457^{*}$ & 0.24 & -0.197 & 0.21 & 0.045 & 0.05 & -0.035 & 0.05 & $0.160 * * *$ & 0.06 & $-0.136^{*}$ & 0.08 \\
\hline Number of children & $-0.551 * * *$ & 0.11 & $-0.420 * * *$ & 0.14 & $-0.111 * * *$ & 0.03 & $-0.321 * * *$ & 0.04 & -0.039 & 0.02 & $-0.197 * * *$ & 0.05 \\
\hline Good health & $0.435^{* * *}$ & 0.04 & $0.177^{* * *}$ & 0.04 & $0.467^{* * *}$ & 0.04 & $0.143^{* * *}$ & 0.04 & $0.524 * * *$ & 0.04 & $0.152 * * *$ & 0.03 \\
\hline Bad health & $-0.178 * * *$ & 0.06 & $-0.113^{* *}$ & 0.06 & -0.106 & 0.07 & -0.045 & 0.05 & $-0.189 * * *$ & 0.06 & -0.046 & 0.05 \\
\hline Ln equivalised h'hold income & $0.101 * * *$ & 0.03 & -0.013 & 0.03 & $0.192 * * *$ & 0.04 & -0.042 & 0.04 & 0.090* & 0.05 & 0.008 & 0.05 \\
\hline Others present during interview & -0.055 & 0.05 & -0.025 & 0.06 & $-0.121 * *$ & 0.05 & -0.042 & 0.04 & $-0.083 *$ & 0.05 & 0.009 & 0.04 \\
\hline Unemployment rate & $-0.022 * *$ & 0.01 & 0.014 & 0.02 & -0.013 & 0.01 & -0.013 & 0.02 & 0.006 & 0.01 & 0.038 & 0.02 \\
\hline BIP per capita & $-0.000 *$ & 0.00 & 0.000 & 0.00 & $-0.000 * * *$ & 0.00 & -0.000 & 0.00 & 0.000 & 0.00 & $0.000 * * *$ & 0.00 \\
\hline Year 2009 & $-0.172 * * *$ & 0.04 & $-0.185 * * *$ & 0.04 & $-0.188 * * *$ & 0.05 & $-0.166 * * *$ & 0.05 & $-0.153 * * *$ & 0.05 & $-0.135 * * *$ & 0.05 \\
\hline Year 2010 & $-0.279 * * *$ & 0.04 & $-0.298 * * *$ & 0.05 & $-0.368 * * *$ & 0.05 & $-0.315^{* * *}$ & 0.05 & $-0.382 * * *$ & 0.05 & $-0.376 * * *$ & 0.05 \\
\hline Year 2011 & $-0.497 * * *$ & 0.05 & $-0.477 * * *$ & 0.06 & $-0.473 * * *$ & 0.05 & $-0.396 * * *$ & 0.06 & $-0.387 * * *$ & 0.05 & $-0.399 * * *$ & 0.07 \\
\hline Year 2012 & $-0.612 * * *$ & 0.05 & $-0.613^{* * *}$ & 0.07 & $-0.501 * * *$ & 0.05 & $-0.412 * * *$ & 0.07 & $-0.430 * * *$ & 0.05 & $-0.453 * * *$ & 0.08 \\
\hline Year 2013 & $-0.759 * * *$ & 0.06 & $-0.729 * * *$ & 0.08 & $-0.598 * * *$ & 0.06 & $-0.481 * * *$ & 0.08 & $-0.396 * * *$ & 0.06 & $-0.417 * * *$ & 0.09 \\
\hline Year 2014 & $-0.820 * * *$ & 0.06 & $-0.818^{* * *}$ & 0.09 & $-0.732 * * *$ & 0.06 & $-0.548 * * *$ & 0.09 & $-0.534 * * *$ & 0.06 & $-0.575^{* * *}$ & 0.11 \\
\hline Year 2015 & $-0.978 * * *$ & 0.06 & $-0.969 * * *$ & 0.10 & $-0.752 * * *$ & 0.07 & $-0.544 * * *$ & 0.10 & $-0.463 * * *$ & 0.06 & $-0.548 * * *$ & 0.13 \\
\hline Constant & $8.103^{* * *}$ & 0.28 & $8.107^{* * *}$ & 0.44 & $6.801 * * *$ & 0.37 & $8.607^{* * *}$ & 0.42 & $6.623^{* * *}$ & 0.45 & $6.429 * * *$ & 0.57 \\
\hline Number of observations & & 14,675 & & 14,675 & & 17,863 & & 17,863 & & 19,880 & & 19,880 \\
\hline Number of groups & & & & 3,607 & & & & 4,173 & & & & 4,384 \\
\hline $\mathrm{R}^{2}$ overall & & & & 0.060 & & & & 0.023 & & & & 0.007 \\
\hline $\mathrm{R}^{2}$ within & & & & 0.059 & & & & 0.036 & & & & 0.020 \\
\hline$R^{2}$ between & & & & 0.072 & & & & 0.022 & & & & 0.007 \\
\hline
\end{tabular}


Table S.5. Satisfaction with family, OLS, and FE estimates, full sample

\begin{tabular}{|c|c|c|c|c|c|c|c|c|c|c|c|c|}
\hline & \multicolumn{4}{|l|}{ 1991-93 } & \multicolumn{4}{|l|}{ 1981-83 } & \multicolumn{4}{|l|}{ 1971-73 } \\
\hline & OLS & & FE & & OLS & & FE & & OLS & & $\mathrm{FE}$ & \\
\hline & Coef & SE & Coef & SE & Coef & SE & Coef & SE & Coef & SE & Coef & SE \\
\hline Unemployed & $-0.406 * * *$ & 0.11 & $-0.266 * * *$ & 0.10 & $-0.247 * * *$ & 0.08 & 0.016 & 0.08 & $-0.295 * * *$ & 0.10 & 0.029 & 0.08 \\
\hline Not in labour force & -0.039 & 0.04 & -0.015 & 0.04 & 0.010 & 0.05 & $0.109 * * *$ & 0.04 & -0.053 & 0.07 & 0.007 & 0.06 \\
\hline Married & 0.256 & 0.18 & $0.413^{* *}$ & 0.20 & $0.477 * * *$ & 0.05 & $0.255^{* * *}$ & 0.05 & $0.722 * * *$ & 0.05 & $0.336 * * *$ & 0.08 \\
\hline Number of children & -0.063 & 0.10 & 0.009 & 0.12 & $0.125^{* * *}$ & 0.03 & $0.096 * * *$ & 0.04 & $0.109 * * *$ & 0.02 & $0.140 * * *$ & 0.05 \\
\hline Good health & $0.327 * * *$ & 0.04 & $0.130 * * *$ & 0.04 & $0.375^{* * *}$ & 0.04 & $0.111^{* * *}$ & 0.03 & $0.382 * * *$ & 0.04 & $0.115^{* * *}$ & 0.03 \\
\hline Bad health & $-0.297 * * *$ & 0.07 & $-0.146 * *$ & 0.06 & $-0.206 * * *$ & 0.06 & -0.038 & 0.05 & $-0.302 * * *$ & 0.06 & $-0.110 * *$ & 0.05 \\
\hline Ln equivalised $\mathrm{h}$ 'hold income & $0.110 * * *$ & 0.03 & 0.011 & 0.03 & $0.208 * * *$ & 0.04 & 0.047 & 0.04 & 0.064 & 0.04 & -0.007 & 0.04 \\
\hline Others present during interview & $0.161 * * *$ & 0.05 & $0.106 * *$ & 0.05 & $0.177^{* * *}$ & 0.04 & $0.115^{* * *}$ & 0.04 & $0.218^{* * *}$ & 0.04 & $0.109 * * *$ & 0.04 \\
\hline Unemployment rate & -0.007 & 0.01 & $0.047 * *$ & 0.02 & -0.017 & 0.01 & -0.009 & 0.02 & $0.023 *$ & 0.01 & $0.038^{* *}$ & 0.02 \\
\hline BIP per capita & -0.000 & 0.00 & 0.000 & 0.00 & $-0.000 * * *$ & 0.00 & -0.000 & 0.00 & -0.000 & 0.00 & -0.000 & 0.00 \\
\hline Year 2009 & $-0.112 * * *$ & 0.04 & $-0.118 * * *$ & 0.04 & $-0.168 * * *$ & 0.04 & $-0.142 * * *$ & 0.05 & $-0.255 * * *$ & 0.04 & $-0.249 * * *$ & 0.04 \\
\hline Year 2010 & $-0.256 * * *$ & 0.05 & $-0.234 * * *$ & 0.05 & $-0.351 * * *$ & 0.04 & $-0.273 * * *$ & 0.05 & $-0.351 * * *$ & 0.04 & $-0.309 * * *$ & 0.04 \\
\hline Year 2011 & $-0.310 * * *$ & 0.05 & $-0.238 * * *$ & 0.06 & $-0.403 * * *$ & 0.05 & $-0.312 * * *$ & 0.06 & $-0.336 * * *$ & 0.04 & $-0.278 * * *$ & 0.06 \\
\hline Year 2012 & $-0.387 * * *$ & 0.05 & $-0.286 * * *$ & 0.07 & $-0.479 * * *$ & 0.05 & $-0.389 * * *$ & 0.07 & $-0.402 * * *$ & 0.05 & $-0.347^{* * *}$ & 0.07 \\
\hline Year 2013 & $-0.346 * * *$ & 0.06 & $-0.231 * * *$ & 0.07 & $-0.566 * * *$ & 0.05 & $-0.477 * * *$ & 0.07 & $-0.393 * * *$ & 0.05 & $-0.331 * * *$ & 0.08 \\
\hline Year 2014 & $-0.405 * * *$ & 0.06 & $-0.297 * * *$ & 0.08 & $-0.665 * * *$ & 0.06 & $-0.561 * * *$ & 0.09 & $-0.430 * * *$ & 0.05 & $-0.371 * * *$ & 0.09 \\
\hline Year 2015 & $-0.434^{* * *}$ & 0.06 & $-0.317 * * *$ & 0.09 & $-0.648 * * *$ & 0.06 & $-0.512 * * *$ & 0.10 & $-0.419 * * *$ & 0.05 & $-0.363 * * *$ & 0.10 \\
\hline Constant & $7.953^{* * *}$ & 0.29 & $7.861 * * *$ & 0.34 & $7.372^{* * *}$ & 0.37 & $8.479 * * *$ & 0.42 & $7.283^{* * *}$ & 0.38 & $8.142^{* * *}$ & 0.49 \\
\hline Number of observations & 14,674 & & 14,674 & & 17,862 & & 17,862 & & 19,868 & & 19,868 & \\
\hline Number of groups & & & 3,607 & & & & 4,173 & & & & 4,382 & \\
\hline $\mathrm{R}^{2}$ overall & & & 0.020 & & & & 0.048 & & & & 0.064 & \\
\hline $\mathrm{R}^{2}$ within & & & 0.018 & & & & 0.018 & & & & 0.019 & \\
\hline$R^{2}$ between & & & 0.024 & & & & 0.061 & & & & 0.092 & \\
\hline
\end{tabular}

Note: ${ }^{* * *} \mathrm{p}<0.01,{ }^{* *} \mathrm{p}<0.05, * \mathrm{p}<0.1$ 